\title{
Numerical study on the response of steel-laminated elastomeric bearings subjected to variable axial loads and development of local tensile stresses
}

\author{
Konstantinos N. Kalfas ${ }^{1}$, Stergios A. Mitoulis ${ }^{2}$, Konstantinos Katakalos ${ }^{3}$ \\ ${ }^{1}$ Bridge Engineer, COSTAIN Engineering \& Construction Limited, London Bridge Station Redevelopment, London, Beazley \\ House,SE13QU,UK, E-mail: kostas.kalfas@,costain.com \\ ${ }^{2}$ Assistant Professor, Faculty of Engineering and Physical Sciences, University of Surrey, Guildford, Surrey GU2 7XH, UK, \\ E-mail:s.mitoulis@surrey.ac.uk,www.mitoulis.com \\ ${ }^{3}$ Research Associate, Department of Civil Engineering, Aristotle University of Thessaloniki, Thessaloniki 54006, Greece, E- \\ mail:kkatakal@,civil.auth.gr
}

\begin{abstract}
Steel-laminated elastomeric bearings are isolation devices which are used extensively in buildings, bridges, nuclear power plants and other structures. Accurate modelling of thebehaviour of these devices is of great importance, as the integrity of isolated structures relies heavily on their response. For many years, steellaminated bearings were designed based on the assumption that they are subjected to compressive and shear loads, as a result of the dead and the horizontal loads,i.e. wind and seismic loads, actingon the structure. It is only very recently that tensile stresses in bearings were studied, as it was observed that local and global tensile stresses might be developed in bearings under seismic excitations. Most importantly, tension within the elastomer might cause local cracks or, in extreme cases, rupture of the elastomer, which might lead to the loss of support of isolated structures. Yet only a few studies exist in the international literature with regard to response of these devices under combined axial and shear loads. The aforementioned gap in the knowledge and the identified rupture of the elastomer of bearings under tensile loads during recent earthquakes comprised the motivation for this research. In this context, this paper examines the response of steel-laminated elastomeric bearings under cyclic shear and variable axial loads and aims to better understand their behaviour with emphasis placed on the tensile stresses within the elastomer, their stiffness and dissipation capacity. Extensive numerical research was conducted with ABAQUS and the Ogden hyperelastic model was used for modelling the elastomeric material. The analyses showed that steel-laminated elastomeric bearings exhibit local tensile stresses, which alter significantly their stiffness and damping ratio. Most importantly, significant tensile stresses within the elastomer were observed locally, even when the bearings were subjected to a combination of shearing and compression.
\end{abstract}

Keywords: seismic isolation; steel-laminated elastomeric bearing; tensile stresses; stiffness; damping ratio; hyperelastic; Ogden

\section{INTRODUCTION}

Steel-laminated elastomeric bearings are common bearings that are used to isolate structures. Their use in structural applications dates in the late 1950s, but research and development of materials and design of the isolators continued over the years until today [1-2]. The application of steel-laminated elastomeric bearings for the seismic isolation of bridges [3] and buildings became morepopularafter the early 1990s, [4-5]. Bearings are used to accommodate movements of the structures, such as dynamic (e.g. seismic) displacements as well as static or quasi-static movements due to creep, shrinkage and thermal effects [6-9] thus transmitting negligible loads to critical structural components, such as bridge piers and foundations. Bearings undertake structural movements and vibrations due to the fact that their shear stiffness is relatively small, thus movements and vibrations are absorbed by shear deformations of the bearings and produces negligible reactions, whilst their stiffness under compressive loads is relatively high to support the weight of the structure[5].

Despite the fact that the current codes of practice describe the behaviour and provide guidelines for the modelling of the bearings, as well as prescriptions and limitations with regard to acceptable design limit states [10-17], only a few design guidelines and studiesexiston steel-laminated elastomeric bearings subjected to tensile stresses when subjected tocyclicloading. However, very recent earthquakes in South America and Asia, the 1999 Chi-Chi earthquake in Taiwan, the 2010 Chile 
Earthquake, the 2011 off the Pacific coast of Tohoku earthquake in Japan [18-21], revealed that bearings might be subjected to tensile stresses locally, even when the global response of the isolator is shearing and axial compression. Thus the design guidelines for isolation bearings must enhance the resilience of these components under cyclic loads [22-23] and especially under large tensile stresses that might cause cracks or rupture of the elastomer, the latter only in extreme design cases.

With regard to code provisions, BS EN 15129 [11] and EN 1337-3 [12] allow the development of tensile stresses within elastomeric bearings up to $2 G$, where $G$ is the shear modulus of the elastomer, and its values range between $0.55 \mathrm{MPa}$ and 1.2 $\mathrm{MPa}$. According to AASHTO [14], tensile stresses up to 2-3 $G$ might be developed within the bearing, hence the limit value of tensile stresses that AASHTO [14] sets, is in the range of 2 to $3 \mathrm{MPa}$, assuming a typical value of $G$ of $1 \mathrm{MPa}$. Similarly, the JRA [17] allows small tensile stresses in bearings, up to $2 \mathrm{MPa}$. In aseismic design code of China, the tensile stress is limited to $1 \mathrm{MPa}[24]$. Eurocode 8 Part2 [10] restricts the development of tensile stresses within bearings under the design seismic combination. Based on the aforementioned codes, it is evident that the tensile response of bearings is a matter that has different design approaches and requires further investigation. Most importantly, none of the codes define whether the allowable tensile stresses refer to the global response of the bearing, i.e. global tension as described by Mitoulis [7], Tubaldi et al. [25] and Mitoulis et al. [26] for bridge bearings, or local tensile effects.

With regard to international literature, emphasis was placed on the shear and compressive response of the isolators under design basis earthquakes by performing numerical tests and experiments [7] [2634], whilst less emphasis was placed on the tensile response of the isolators [4] [6] [31-38]. Additionally, Cardone \& Perone [39] based their research on the assumption that there is no development of tensile stresses in the bearings. However, Stanton et al. [1] examined all possible deformations that the bearing can sustain. The latter research concluded that elastomeric bearings can undertake shearing, compression and rotations, but recommend that the isolators should not be subjected tosignificant tensile stresses. For design earthquakes, the influence that the earthquakes have on the mechanical properties of bearings (shear stiffness and damping ratio) will be relatively small, however stronger seismic motions and larger displacements change the bearing properties dramatically [27] [39-40]. Reliance of current design practice is based on the fact that elastomeric bearings are subjected to significant compressive loads due to the self-weight of the supported structure, thus the possibility of tensile loading is adequately low.

One of the first and comprehensive studies on the behaviour of rubber cylinders in tension was performed by Gent \& Lindley [41]. This experimental research was completed almost a decade after the appearance of Mooney-Rivlin hyperelastic model [42-43] and before the appearance of Ogden hyperelastic model [44]. It was observed that when applying small tensile loads and after exceeding the theoretical yielding point, i.e. development of cavities within the rubber, internal cracks (cavities) were developedin all the specimens used. Nonetheless, rupture occurred only in samples of small thicknesses. Gent \& Lindley [41] proved for the first time that there is damage in the internal compound of the elastomer when tensile stresses with the value of $2.75 \mathrm{MPa}$ was imposed to it and this damage leads to severe degradation of the strength of the elastomer. Iwabe et al. [45] tested experimentally the effect of tension on steel-laminated elastomeric bearings. Tensile strains up to $100 \%$ were imposed to the bearing together with shear strains up to $200 \%$. The study concluded that increasing non-linear effects were observed for increased tensile strains, however bearings did not exhibit cavitation. However, even when pure tensile strain of $100 \%$ of the thickness of the elastomer was imposed to the bearing, the rubber did not rupture, which indicates that bearings have high tensile capacity. Additionally, recent studies revealed that the tensile stiffness of bearings is important to describe the bearing response and thus the response of isolated structures. Also the bearing exhibits non-linear behaviour for tensile stresses larger than $1-2 \mathrm{MPa}$, whilst its tensile stiffness is approximately equal to $1 / 7$ of the compressive one, based on the tangent stiffness measured near origin [24]. Nonetheless, design guidelines usually do not take into accountthe axial stiffness of the isolators or prescribe that the tensile stiffness is similar to the compressive one, indicating that the axial response of the elastomeric isolators is neither well understood nor studied.

This paper aims to better understand the behaviour of steel-laminated elastomeric bearings. This was achieved by defining the variation of important design properties of the isolators, i.e. stiffnessand damping ratio, and also by identifying local tensile stresses when the isolators are subjected tolarge cyclic shear displacements and variable axial loads. The aforementioned loads correspond to shear 
strains, ranging from $125 \%$ to $375 \%$, whilst vertical loads range from $2 \mathrm{MPa}$ tensile to $14 \mathrm{MPa}$ compressive stresses. It is noted that the shear strain corresponds to shear displacements over the total thickness of the elastomer, hence not taking into account thethickness of the metal plates of the bearing. ABAQUS Ver. 6.13 [46] [47] [48] was used for the analyses and different boundary conditions, target displacements and axial loads were considered to cover a wide range of bearing applications on bridges. The hyperelastic Ogden material [44] was used for allthe analyses.

\section{VALIDATION OF THE NUMERICAL MODEL OF THE BEARING AND PARAMETRIC STUDY}

\subsection{Material Properties}

The calibration of the models of steel-laminated elastomeric bearings analysed in this paper was based on the study of Ohsakiet al [36]. The latter numerical models were developed in ABAQUS and compared against results available in the literature [36] [47]. This calibrated numerical model was considered to be the reference of this study. Subsequently, the modelled bearings were subjected to shear and variable axial loads. The Ogden hyperelastic material model [44] was used for modelling the elastomeric layers of the reference bearings as it was found to be the most accurate model for elastomeric materials representing natural rubber. The hyperelastic material describes accurately the stresses, the strains that are developed within the elastomer and the energy dissipation (hysteresis) within the bearing. The Ogden strain energy density function is defined in Equation 1 below:

$$
\mathrm{U}=\sum_{n=1}^{2} \frac{\mu_{n}}{\alpha_{n}}\left(\bar{\lambda}_{1}^{\alpha_{n}}+\bar{\lambda}_{2}^{\alpha_{n}}+\bar{\lambda}_{3}^{\alpha_{n}}-3\right)+4.5 B\left(J^{\beta}-1\right)^{2}
$$

In Equation 1 , the hyperelastic parameters are $\mu_{1}=0.41 \mathrm{MPa}, \quad \alpha_{1}=1.6$, $\mu_{2}=0.0012 \mathrm{MPa}, \alpha_{2}=6.2$ and $\beta=1 / 3$. These values were obtained from experiments of a rubber bearing with variable pressure levels as for example in the paper of Bradley et al. [35]. Where $J$ is the elastic volume ratio and $\bar{\lambda}_{1}, \bar{\lambda}_{2}, \bar{\lambda}_{3}$ are the deviatoric stretches, i.e. the principal values of right stretch tensor. The values of the shear modulus and the Poisson ratio are calculated as per the reference case and are described by Equations 2 and 3:

$$
\begin{aligned}
& \mathrm{G}=\alpha_{1} \mu_{1}+\alpha_{2} \mu_{2} \Rightarrow \mathrm{G}=0.66344 \mathrm{MPa} \\
& v=\left(\frac{3 B}{G_{b}}-2\right) /\left(\frac{6 B}{G_{b}}-2\right) \Rightarrow v=0.49989
\end{aligned}
$$

For this particular research, it is noted, that the Mullins' effect [49-50], which causes reduction of the bulk modulus of the elastomer during the first cycles of the bearing loading, was not taken into account, and the bearings were considered scragged. This assumption was based on the fact that bridge bearings are subjected to continuous cyclic movements due to the thermal expansion and contraction of the deck. It is noted that Mullins effect occurs predominanty during the first cycle of loading, whilst the reduction of the bulk modulus of the elastomer is incrementally smaller during the subsequent cycles, up until the stabilization in the hysteresis [49].

\subsection{Geometry and loading}

Figure 1 and Table 1 describe in detail the geometry of the reference bearing. This model is referred hereinafter as Non Linear bearing and denoted as $N L$. The circular bearing has a diameter of $700 \mathrm{~mm}$. Circular plates of diameter $1000 \mathrm{~mm}$ were used as the top and bottom anchor plates of the bearing. The steel-laminated elastomeric bearing numerical model has a total of 30 layers of elastomer, 29 steel shims and two anchor plates. The total thickness of the elastomer is $120 \mathrm{~mm}$ i.e. 30 elastomeric layers of $4 \mathrm{~mm}$ thickness each. The total thickness of the steel shims is $89.9 \mathrm{~mm}$ i.e. 29 steel shims of $3.1 \mathrm{~mm}$ each. The two top and bottom anchor plates have a thickness of $28 \mathrm{~mm}$ each. Thus, the total height of the reference bearing is $120 \mathrm{~mm}+89.9 \mathrm{~mm}+2 \times 28 \mathrm{~mm}=265.9 \mathrm{~mm}$. The diameter of the elastomeric 
layers and steel shims is $700 \mathrm{~mm}$ and the diameter of the anchor plates is $1000 \mathrm{~mm}$. At the centre of the reference bearing there is a hole with a diameter of $15 \mathrm{~mm}$.

The elastomeric layers and steel shims were discretised with linear wedge elements of type C3D6. Geometric non-linearities are incorporated in the analysis.

(Figure 1)

Figure 1.Meshing of the reference $\mathrm{NL}^{\mathrm{C}}$ elastomeric bearing in ABAQUS: (a) side viewand bottom anchor plate boundary conditions, (b) three dimensional model, (c) section.

(Table 1)

Table 1.Geometry of the reference bearing $N L^{C}$.

The bottom anchor plate of the model is fixed. Shear displacement of $450 \mathrm{~mm}$ and simultaneous axial pressure is imposed to the top anchor plate of the bearing. Initially, the bearing was subjected to one full cycle of shear corresponding to a shear strain of $375 \%$, thus the shear displacement is $450 \mathrm{~mm}$. Figure 2 shows the comparison of the results of the numerical model analysed in this paper against the available results in the literature [36]. It is observed that he reference bearing (grey diagram) reproduces accurately the force-deformation diagram of the available numerical and experimental results ofprevious studies (dashed lines) [36]. Also, the experimental results were modelled with acceptable accuracy for both the loading and the unloading of the bearing. This reference model was used inthe parametric study presented in the following sections of this paper.

(Figure 2)

Figure 2.Validation of the reference bearing model against the available numerical and experimental results.

\subsection{Parametric study on the response of steel-laminated elastomeric bearings}

Variable axial loads, compressive or tensile, ranging from $2 \mathrm{MPa}$ (tensile) to $-14 \mathrm{MPa}$ (compressive) with the intermediate values of $0,-2,-5$ and $-10 \mathrm{MPa}$ and shear strains of $375 \%$ are applied to the reference bearing to identify the variation of its behaviour on the basis of global response parameters (stiffness and dissipation capacity) as well as local effects, i.e. concentration of tensile stresses. During the analyses it was evident that the boundary conditions played an important role with regard to tensile stresses that were developed within the elastomer. Thus, apart from the variation of the axial load, two different boundary conditions were considered: one considering that the bearing is fixed at the bottom, but free to rotate at the top and a second one that hadUX=UY=UZ=RX=RY=RZ=0 at the bottom, i.e. fixed, and $R X=R Y=R Z=0$ at the top, i.e. the upper anchor plate rotation is restricted and remains parallel to the bottom one, but it is free to movealong $\mathrm{X}, \mathrm{Y}, \mathrm{Z}$ axes. The boundary conditions chosen in this study also reflect the two cases that are met in practical applications, where the bearings might exhibit significant rotations, thus allow for relative rotations of the upper and the lower anchor plates of the isolator or the isolator exhibits negligible rotations, thus the upper anchor plate displaces almost parallel to the bottom one. In real applications the rotation of the isolator should be kept within allowable limits [1], thus the cases analysedin this paper provide an envelope of the prospected responses of isolators.

Table 2 shows the loading conditions that were analysed, i.e. the axial load, either tension or compression together with a target shear strain of $375 \%$. This shear strain was chosen in order to better understand the response of the isolators when subjected to large shear displacements, as bearings exhibit instabilities, e.g. buckling for larger shear strains. On the other hand, the behaviour of isolators under tensile stresses was also studied. In particular a maximum tensile stress of 2 MPawas applied to the bearings simultaneously with shear strain of $375 \%$.

(Table 2)

Table 2.Analysesof the reference bearing for variable axial loads, different boundary conditions, shear strain $375 \%$ and different number of cycles of loading - unloading. 
With regard to number of loading cycles, one full cycle of loading-unloading at $\pm 375 \%$ shear strain was imposed to the isolator. To obtain the hysteresis loops from the analyses and to capture the damping properties of the bearing, the hysteretic parameters of ABAQUS were used. The hysteretic parameters with their values derived from the paper of Bergström \& Boyce [51].The Stress Scaling Factor, which influences the damping ratio of the isolators, was taken 1.6 based on the research of Bergström \& Boyce [51]. This factor gives reliable results for low-damping rubber bearings, having a damping ratio smaller than $10 \%[10]$. The additional hysteretic parameters which were taken into consideration for this study, and their values, obtained from the aforementioned paper are as follows: Creep Parameter $A=0.56$, Effective Stress Exponent $m=4$ and Creep Strain Exponent $C=-1$. All these parameters are unitless. It is noted that, based on reference [51], the hysteresis loop which is produced due to the cyclic loading is not related to the Mullins effect. Also, analyses were conducted for a total of two cycles, shown in Figure 3b, however the results were found to be identical as the bearing force displacement curves followed the same loading path, i.e. the one of the first cycle. The analyses herein assume that the elastomer exhibits no cavitation.

\section{RESPONSE OF ELASTOMERIC BEARINGS AND LOCAL TENSILE STRESSES}

\subsection{Influence of the axial load on the stiffness and damping of the bearing}

From figure $3 \mathrm{a}$ it is observed that there is a reduction of the secant stiffness of the bearing when the compression is increased. Generally, the higher the axial pressure that is imposed the smaller the value of horizontal reaction that is developed at the bottom anchor plate, i.e. the smaller the stiffness for the same target displacement. The former observation is in line with previous studies [52]. However, this was found to be the case when the target displacements are larger than $200 \mathrm{~mm}$, i.e. shear strains larger than $167 \%$. For smaller shear strains, the secant stiffness was found to be initially increased, then decreased and then increased again for larger shear strains when the vertical compression is 14 $\mathrm{MPa}\left(N L_{6}\right)$, whilst the behaviour of the bearing was found to be almost linear when the compression is relatively low, i.e. up to $2 \mathrm{MPa}\left(N L_{3}\right)$.

With regard to the behaviour of the bearing for the target shear strain of $375 \%$, in combination with free movement of the upper anchor plate (i.e. the upper anchor plate is free to rotate, $U X, U Y, U Z, R X$, $R Y, R Z \neq 0)$, the shear stiffness undergoes negligible reduction when the axial compression increases from zero $\left(N L_{2}\right)$ to $2.0 \mathrm{MPa}\left(N L_{3}\right)$ and from $2.0 \mathrm{MPa}\left(N L_{3}\right)$ to $5.0 \mathrm{MPa}\left(N L_{4}\right), 12.9 \%$ when the axial load increases from 5.0 $\mathrm{MPa}\left(N L_{4}\right)$ to $10 \mathrm{MPa}\left(N L_{5}\right)$ and $17.5 \%$ when the axial load increases from pressure $10 \mathrm{MPa}\left(N L_{5}\right)$ to $14 \mathrm{MPa}\left(N L_{6}\right)$. It is noted that the stiffness for the aforementioned comparisons corresponds to the secant stiffness at the maximum shear strain of the bearing, i.e. $125 \%$, $250 \%$ and $375 \%$. Based on the hysteresis loops shown in Figure $3 \mathrm{a}$ and $3 \mathrm{~b}$ the damping ratio $\xi$ was calculated based on Equation 4 [5]:

$$
\xi=\frac{A}{2 * \pi * K_{e f f} * D^{2}}
$$

In Equation 4, $A$ is the area of the hysteresis loop, $K_{\text {eff }}$ is the effective stiffness of the bearing measured at the maximum target displacement of $150 \mathrm{~mm}, 300 \mathrm{~mm}$ and $450 \mathrm{~mm}$, respectively for the shear strains of $125 \%, 250 \%$ and $375 \%$, and $D$ is the displacement amplitude. Based on the results of the numerical model, it was found that the damping ratio increases by $29 \%$ when the axial load increases from compression $5 \mathrm{MPa}\left(N L_{4}\right)$ to compression $10 \mathrm{MPa}\left(N L_{5}\right)$.

(Figure 3)

Figure 3.Response of the reference steel-laminated elastomeric bearing for variable axial loads(shear strain375\%)for (a) one cycle of loading $\left(N L_{1},-N L_{6}\right)$ and (b) two cycles of loading $\left(N L_{10}-N L_{15}\right)$. 
Additional analyses were conducted to assess the influence of local tensile stresses on the response of the bearing. Taking into account that acceptable tensile stresses are of the order of 2-3 MPa, a uniform tensile stress of $2 \mathrm{MPa}\left(N L_{1}\right)$ was applied axially to the isolator together with a shear strain of $375 \%$. The stiffness and the damping of the isolator under tension (2 MPa) was then compared to the response of the bearing under compression, the latter having a compression of $2 \mathrm{MPa}\left(\mathrm{NL}_{3}\right)$. Also, the analyses only considered global (also known as hydrostatic) stresses on the bearing, i.e. uniform tensile or compressive stresses.

Figure 4 shows the force-displacement curves of the same bearing when the latter is being subjected to either tension or compression together with maximum shear strains of $375 \%$ and the upper anchor plate is free to rotate (i.e. UX, UY, UZ, RX, RY, RZ $\neq 0$ for the upper anchor plate). The figure shows that the shear stiffness and damping ratio of the isolator are not influenced significantly when low axial strains (either tensile or compressive) are imposed on it. For example, when the axial load is tensile $2 \mathrm{MPa}\left(N L_{1}\right)$ the shear stiffness is $2398 \mathrm{kN} / \mathrm{m}$. The corresponding stiffness when axial compression of $2 \mathrm{MPa}\left(N L_{3}\right)$ is applied is $2285 \mathrm{kN} / \mathrm{m}$ thus the increase in the stiffness is approximately $5 \%$, which is considered to be within the expected variation of the properties of the isolator.

\section{(Figure 4)}

Figure 4. Shear force-displacement response of the steel-laminated elastomeric bearings for axial tension (2 MPa) and axial compression (2 $\mathrm{MPa}$ ) (shear strain is $375 \%)$.

Additionally, buckling is taken into account, due to large deformation, but no buckling has been observed, based on the calculationprocessthat is proposed in the BS EN 11529:2009 [11] and has been used in order to validate the fact that no buckling is developed during the analyses.

\subsection{The effect of boundary conditions onthe stiffness and the damping of the bearing}

As it was mentioned before, the boundary conditions of bearings with regard to rotations of the anchor plates vary significantly based on the response of the structural components upon which the bearings are anchored. For example the isolation bearing on buildings have a predominantly translational movement, whilst rotations are negligible. However, bearings used on piers to support bridge decks might exhibit significant rotations due to the deflection of the piers and the rocking of the foundation [53]. Figures 5, 6, and 7 illustrate the bearing responses for different boundary conditions of the bearings, i.e. when the top anchor plate is free to rotate or its rotations are restricted.

More specifically, Figures 5, 6 and 7show the hysteresis loops of the bearings subjected to shear loading and axial compressive stresses of $5 \mathrm{MPa}\left(N L_{4}\right.$.- $\left.^{-} N L_{7}\right), 10 \mathrm{MPa}\left(N L_{5}\right.$.- $\left.^{-} N L_{8}\right)$ and $14 \mathrm{MPa}$ ( $N L_{6}$.- $N L_{9}$ ) correspondingly. From these figures, it is evident that the stiffness of the bearing is increased when the top anchor plate is fixed, which is reasonable based on the fact that additional restraints increase the stiffness of the isolator. What is of interest in this case is the fact that the shear stiffness of the isolator is increased by $10.2 \%$ when the anchor plate rotation is restricted and the compressive load is $5 \mathrm{MPa}$, whilst the increase in the stiffness is $9 \%$ and $32.1 \%$ when the compression of the bearing is $10 \mathrm{MPa}$ and $14 \mathrm{MPa}$ respectively. The latter observation is important as the stiffness of the isolator is of great importance to the design of structures subjected to static or dynamic loads. For example, the design of bridge abutments, piers and foundations is based on the period of the isolated structure, whilst the forces transmitted from the bearings to the substructures are the ones used for selecting the reinforcements and the foundation size. Additionally, the design of the expansion joints is dependent on the displacements of the deck and thus the stiffness of the isolation system.

With regard to damping, the numerical model shows that the damping ratio of the bearing is decreased when the rotation of the upper anchor plate is restrained. When the axial pressure is $5 \mathrm{MPa}$ there is a negligible decrease of its damping ratio when the top anchor plate rotation is fixed as opposed to the case where the top anchor plate is free to rotate. The corresponding decreases when the axial load is 
$10 \mathrm{MPa}$ or $14 \mathrm{MPa}$ are $27.9 \%$ and $42.3 \%$ respectively. Thus, the boundary conditions of the isolator seem to influence significantly both the stiffness and the damping of the isolator. Also, it seems that the higher the vertical load on the isolator the more important is the role of the boundary conditions of the isolator, as both its stiffness and damping might change drastically, thus affecting the overall structural response of the isolated structure.

Another notable effect of the bearing boundary condition is the fact that the response of the bearing in terms of shear-force displacements, deviates significantly from the linear behaviour when the boundary conditions change. For example, Figure 5 shows that when the rotation of the upper anchor plate of the bearing is restrained the isolator has a response that is essentially linear up until the maximum displacement of $450 \mathrm{~mm}$. Contrarily, the behaviour of the isolator is different when the bearing upper anchor plate is free to rotate. In the latter case, the bearing stiffness decreases after the displacement of $240 \mathrm{~mm}$, i.e. after a shear strain of $200 \%$ is applied, whilst its stiffness increases again at higher shear strains, i.e. $250 \%$ that corresponds to shear displacement of $300 \mathrm{~mm}$. This behaviour was observed before based on shear tests against which numerical models were validated [25].

(Figure 5)

Figure 5. Shear force-displacement response of the steel-laminated elastomeric bearings for different boundary conditions (compression $5 \mathrm{MPa}$ and shear strain $375 \%$ ).

(Figure 6)

Figure 6. Shear force-displacement response of the steel-laminated elastomeric bearings for different boundary conditions (compression $10 \mathrm{MPa}$ and shear strain $375 \%$ ).

(Figure 7)

Figure 7. Shear force-displacement response of the steel-laminated elastomeric bearings for different boundary conditions (compression $14 \mathrm{MPa}$ and shear strain $375 \%$ ).

\subsection{Development of local tensile stresses}

For identifying the potential tensile stresses (noted as S33 in the following figures) within the bearing, additional analyses were performed with the reference bearing considering again variable boundary conditions (free or restraint rotation of the upper anchor plate) and a range of shear strains i.e. $125 \%$, $250 \%$ and $375 \%$. The analyses performed are shown in Table 3 (analyses 16 to 21). The axial load was kept constant in this case and equal to $10 \mathrm{MPa}$, which is considered to be a relatively high compressive load for bridge bearings. It is recognised that the maximum compressive stresses chosen, i.e. 10 and $14 \mathrm{MPa}$, are relatively large for bridge applications and for isolated structures in general. However, Eurocode 8 Part 2 [10] allows maximum shear strains, due to vertical compression of the isolator, up to 2.5. Thus extreme earthquake excitations on bridges, which might lead to large axial loads and/or to potential local tensile stresses, are analysed in this paper, with the aim to better understand how these loads might affect the performance of the isolators.

(Table 3)

Table 3.Analyses of the reference bearing for variable shear strains and boundary conditions (axial compressive load $10 \mathrm{MPa}$ ).

Figures 8-13 show vertical sections along the diameter of the reference circular bearing with the same axial compressive load of $10 \mathrm{MPa}$ and variable shear strains and boundary conditions as described by Table 3. It is noted that the values of the numerically calculated stresses within the elastomeric bearings did not consider the potential of local cavitation and hence the stresses are hypothetical in the sense that the elastomer remains elastic.Figures 8 and 9 show the vertical sections of the reference bearing at shear strain $125 \%$ i.e. shear displacement of $150 \mathrm{~mm}$ and upper anchorplate free to rotate ( $\left.N L_{16}\right)$ and with rotational restraint $\left(N L_{17}\right)$ respectively. Subsequently, Figures 10 and 11 illustrate the sections of the reference bearing subjected to shear strain of $250 \%$ i.e. shear displacement of 300 
$\mathrm{mm}$ and variable boundary conditions $\left(N L_{18}, N L_{19}\right)$. Figures 12 and 13 show vertical sections of the reference bearing with shear strain of $375 \%$ i.e. shear displacement of $450 \mathrm{~mm}$ and variable boundary conditions $\left(N L_{20}, N L_{21}\right)$. Thus, the upper plate remains horizontal and parallel to the bottom plate in Figures 9, 11 and 13, whilst the upper plate rotates in Figures 8, 10 and 12.

It is observed that when the shear strain that is imposed to the bearing is $125 \%$, then the upper anchor plate exhibits a rotation of 2.4 degrees. The corresponding rotation when the shear strain is $250 \%$, which is shown in Figure 11, is 3.6 degrees and 4.4 degrees for shear strain of $375 \%$, shown in Figure 12. The grey areas that are shown in Figures 8-13 are areas where local tensile stresses are developed. It is observed that these areas are becoming more pronounced when the shear displacement increases, despite the fact that the external axial load was a considerable compressive load of $10 \mathrm{MPa}$. Moreover, the distribution of the tensile stresses varies significantly for the two different boundary conditions considered for the top anchor plate, with the local tensile stresses being significantly higher when the upper anchor plate is free to rotate. The latter explains the rotation limits proposed in design guidelines of steel laminated rubber bearings. Also, local tensile stresses become higher when the shear displacement increases. For example, the maximum local tensile stress on Figure 9 is $1.46 \mathrm{MPa}$ and this corresponds to a shear strain of $125 \%$, whilst the local tensile stress is $2.14 \mathrm{MPa}$ when the shear strain is $375 \%$. Finally, the comparison between Figures 8, 10 and 12 with the Figures 9, 11 and 13 shows that in the latests (i.e. at the cases where there is restraint of the rotation of the upper anchor plate), there is development of local tensile stresses at the top left and bottom right areas of the bearing with concentration of compressive stresses at the centre of it, while at the case where the upper anchor plate is free to rotate, there is concentration of local tensile stresses at the right area of the bearings with concentration of compressive stresses at the left area of the bearing. When it comes to small shear strain of $125 \%$ with pressure of $10 \mathrm{MPa}$ and the top anchor plate free to rotate, there is development of tensile stresses at the centre of the bearing with development of compressive stresses at the perimeter of the bearing. This is a condition which appears due to the flexibility of the upper anchor plate.

(Figure 8)

Figure 8. The axial stresses within the bearing for compressive load of $10 \mathrm{MPa}$, shear strain $125 \%$ and upper layer of the reference bearing free to rotate $\left(N L_{16}\right)$ (vertical section at bearing diameter).

(Figure 9)

Figure 9. The axial stresses within the bearing for compressive load of $10 \mathrm{MPa}$, shear strain $125 \%$ and application of rotational restraint of the upper layer of the reference bearing $\left(N L_{17}\right)$ (vertical section at bearing diameter).

(Figure 10)

Figure 10. The axial stresses within the bearing for compressive load of $10 \mathrm{MPa}$, shear strain $250 \%$ and upper layer of the reference bearing free to rotate $\left(N L_{18}\right)$ (vertical section at bearing diameter).

(Figure 11)

Figure 11. The axial stresses within the bearing for compressive load of $10 \mathrm{MPa}$, shear strain $250 \%$ and application of rotational restraint of the upper layer of the reference bearing $\left(N L_{19}\right)$ (vertical section at bearing diameter).

(Figure 12)

Figure 12. The axial stresses within the bearing for compressive load of $10 \mathrm{MPa}$, shear strain $375 \%$ and upper layer of the reference bearing free to rotate $\left(N L_{20}\right)$ (vertical section at bearing diameter). 
(Figure 13)

Figure 13. The axial stresses within the bearing for compressive load of $10 \mathrm{MPa}$, shear strain $375 \%$ and application of rotational restraint of the upper layer of the reference bearing ( $\left.N L_{21}\right)$ (vertical section at bearing diameter).

Figure 14 shows the position of the top, middle and bottom rubber layer which is used in order for the development of local tensile stresses to be illustrated. Figures $15 \mathrm{a}, \mathrm{b}$ and $\mathrm{c}$ which depict horizontal sections of the top, middle and bottomrubber layer when the upper layer is free to rotate, by emphasizing to the areas where the tensile stresses are developed, enhance the observation that large tensile stresses are developed within the bearing. These areas are depicted with grey colour. In Figure $15 \mathrm{a}$, where the shear strain imposed is $125 \%$, there is development of compressive stresses at the upper half of the bearing (y-axis is the direction of the imposed shear strain), while tensile stresses are developed at the centre of the bearing. When the shear strain is increased to $250 \%$ then there is development of tensile stresses in the top, middle and bottom rubber layer, with values larger than 10 $\mathrm{MPa}$, which are concentrated at the bottom half of the bearing (i.e. at the opposite direction of the imposed shear strain).Finally, when the shear strain is increased to $375 \%$, extremelocal tensile stresses are developed in the bearing.The tensile stresses are developed within the area, where there is rotation of the bearing (right hand side in Figures 10 and 12) and furthermore, the tensile stresses that are developed within the body of the elastomer are higher at the boundaries of the bearing.

(Figure 14)

Figure 14. Three-dimensional view of the bearing indicating the position of the rubber layers shown in figures 15 and 16 below.

(Figure 15)

Figure 15. Axial stresses of the bearings at horizontal sections at the top, middle and bottom rubber layer. Gray areas indicate tensile stresses. Compressive load $10 \mathrm{MPa}$ and upper layer of the reference bearing free to rotate, shear strain: (a) $125 \%\left(N L_{16}\right)$, (b) $250 \%\left(N L_{18}\right)$, (c) $375 \%\left(N L_{20}\right)$.

Nonetheless, when a rotational restraint was applied on the upper anchor plate of the bearing, then there is not development of large tensile stresses towards the edgesof the bearing. Figures 16a, $b$ and cdepict horizontal sections of the top, middle and bottomrubber layer of the reference bearing when the shear strains that are imposed to it are $125 \%, 250 \%$ and $375 \%$ respectively and there is rotational restraint of the upper layer. Based on these figures, development of compressive stresses is attainedin the areas closer to the centre of the bearing. However, tensile stresses were observed at the edges of the rubber layer which do not exceed 1.70 MPa. Thus, the boundary conditions and the shear strain of the bearing influences strongly both the magnitude and the distribution of the tensile stresses within the elastomeric bearing.

(Figure 16)

Figure 16. Axial stresses of the bearings at horizontal sections at the top, middle and bottom rubber layer. Gray areas indicate tensile stresses. Compressive load of $10 \mathrm{MPa}$, application of rotational restraint of the upper layer, shear strain: (a) $125 \%\left(N L_{17}\right)$, (b) $250 \%\left(N L_{19}\right)$, (c) $375 \%\left(N L_{21}\right)$.

\section{CONCLUSIONS}

A numerical study was performed to better understand the behaviour of steel-laminated elastomeric bearings under variable (tensile and compressive) axial loads, boundary conditions and target shear strains. A hyperelastic material model (Ogden) was used to model the behaviour of the elastomer and was calibrated against numerical and experimental results available in the literature. Emphasis was placed on the stiffness and the dissipation capacity of the isolators and the local tensile stresses which are developed within the bearing. The numerical study on ABAQUS came up with the following conclusions: 
- An increase of the imposed compression leads to a significant decrease of the shear stiffness of the isolator. When the compression on the bearings increased from $5 \mathrm{MPa}$ to $10 \mathrm{MPa}$ the stiffness was reduced by approximately $13 \%$. The opposite was found to be valid for the dissipation capacity of the isolator, as the damping ratio of the isolator was increased by $29 \%$ when the compressive stress was increased from $5 \mathrm{MPa}$ to $10 \mathrm{MPa}$.

- The influence of different boundary conditions on the behaviour of the bearing was examined on the basis of two cases that were deemed to provide an envelope of the anticipated boundary conditions, i.e. free rotation of the anchor plates of the isolator or restricted rotations of the isolator. The numerical study showed that the rotational restraint of the bearing leads to higher shear stiffness and smaller damping ratio. More specifically, under the same axial compressive stress (10 $\mathrm{MPa}$ ) and for the same target shear strain $375 \%$ the bearing that has its anchor plates restricted to rotate was found to have shear stiffness $9 \%$ larger and damping ratio approximately $27.9 \%$ smaller than the bearing that was free to rotate.

- Development of local tensile stresses was observed within the analysed bearing, despite the fact that the external load on the bearing was global shearing and axial compression. Tensile stresses exceeding $5 \mathrm{MPa}$ were found to be developed within the elastomer when the bearing was subjected to shear strains larger than $125 \%$ and to vertical compressive stress of $10 \mathrm{MPa}$, whilst allowing the bearing to rotate freely, i.e. the bearing has no rotational restraints. However, the latter case (i.e. free bearing rotation) is not common in practical applications, where the two anchor plates are expected to exhibit minimal relative rotations. The analysis of the bearing when its anchor plates remained parallel throughout the analysis (rotations restricted) yielded maximum local tensile stresses smaller than $2 \mathrm{MPa}$. Thus providing designs where bearings exhibit minimal rotations minimise the potential development of adverse local tensile effects.

What is deemed to be important in order to accurately model, predict the behaviour and properly design isolated structures with steel-laminated elastomeric bearings is to better understand the response of the isolators under variable axial loads and different boundary conditions. This is related to the need for accurate predictions of both the stiffness and the damping of the isolators and thus the behaviour of the isolated structure. The actual behaviour of the isolators under these local tensile effects is not entirely understood or addressed to date.

\section{REFERENCES}

[1] Stanton, J., F., Roeder, C., W., Mackenzie-Helnwein, P., White, C., Kuester, C., Craig, B., 2007. Rotation Limits for Elastomeric Bearings. National Cooperative Highway Research Program (NCHRP), Washington D.C.: Transportation Research Board.

[2] Aria, M., Akbari, R., 2013. "Inspection, Condition Evaluation and Replacement of Elastomeric Bearings in Road Bridges". Structure and Infrastructure Engineering, Vol. 9 (9), pp. 918-934.

[3] Manos, G., C., Mitoulis, S., A., Sextos, A., 2011. "A Knowledge Based Software for the Design of the Seismic Isolation System of Bridges". Bulletin of Earthquake Engineering, Vol. 10 (3), pp. 1029-1047

[4] Constantinou, M., C., Whittaker, A., S., Kalpakidis, Y., Fenz, D., M., Warn, G., P., 2007. Performance of Seismic Isolation Hardware under Service and Seismic Loading. Multidisciplinary Center for Earthquake Engineering Research (MCEER), New York: University at Buffalo.

[5] Naeim, F., Kelly, J., M., 1999. Design of Seismic Isolated Structures-From Theory to Practice. John Wiley \& Sons, New York: U.S.A.

[6] Nguyen, H., H., Tassoulas, J., L., 2010. "Directional Effects of Shear Combined with Compression on Bridge Elastomeric Bearings". Journal of Bridge Engineering, Vol. 15 (1), pp. 73-80.

[7] Mitoulis, S., A., 2014. "Uplift of Elastomeric Bearings in Isolated Bridges Subjected to Longitudinal Seismic Excitations". Structure and Infrastructure Engineering, pp.1-16. 
[8] Moghadam, S., R., Konstantinidis, D., 2014. The Effect of slip on the Compressive Behavior of Unbonded Rubber Pads: A Finite Element Approach. $10^{\text {th }}$ National Conference on Earthquake Engineering, Frontiers of Earthquake Engineering, 21-25July 2014, Anchorage, Alaska.

[9] Konstantinidis, D., Kelly, J., M., Makris, N., 2008. Experimental Investigation on the Seismic Response of Bridge Bearings. Earthquake Engineering Research Center, University of California.

[10] EN 1998-2, 2005.Eurocode 8: Design of Structures for Earthquake Resistance, Part 2: Bridges. Brussels, Belgium: European Committee for Standardization.

[11] BS EN 15129: 2009, 2010. Anti-seismic Devices. BSI British Standards.

[12] EN 1337-3: 2005, 2005. Structural bearings - Part 3: Elastomeric Bearings. Brussels: European CommitteeforStandardization.

[13] DIN 4141-14:2003-051985-09, 19852003. Lager im Bauwesen- Bewehrte Elastomerlager, Bauliche Durch bildung und Bemessung. Germany.

[14] American Association of State Highway and Transportation Officials, AASHTO, 2014. Guide Specifications for Seismic Isolation Design. $4^{\text {th }}$ Ed. Washington, DC.

[15] American Association of State Highway and Transportation Officials, AASHTO, 2014. LRFD Bridge Design Specifications. $7^{\text {th }}$ Ed., with 2015 and 2016 Interim Revisions, Washington, DC.

[16] Service d'études techniques des routes etautoroutes-Sétra, 2007. Laminated Elastomeric Bearings- Use on Bridges, Viaducts and Similar Structures. Technical Guide. Bagneux Cedex, France.

[17] Japan Road Association, JRA, 2011. Bearing Support Design for Highway Bridges. Tokyo, Japan.

[18] Lu, C.H., Liu, K.Y., Chang, K.C., 2011. "Seismic Performance of Bridges with Rubber Bearings: Lessons Learnt from the 1999 Chi-Chi Taiwan Earthquake". Journal of the Chinese Institute of Engineers, Vol. 34 (7), pp. 889-904.

[19] Kwon, O.S., Jeong, S.H., 2013. "Seismic Displacement Demands on Skewed Bridge Decks Supported on Elastomeric Bearings". Journal of Earthquake Engineering, Vol. 17, pp. 9981022.

[20] Takahashi, Y., 2012. Damage of Rubber Bearings and Dampers of Bridges in 2011 Great East Japan Earthquake. Proceedings of the International Symposium on Engineering Lessons Learned from the 2011 Great East Japan Earthquake, 1-4 March 2012, Tokyo, Japan, pp. 13331342.

[21] Earthquake Engineering Research Institute, EERI, 2011. Learning from Earthquakes Bridge Performance in the Mw 9.0 Tohoku,Japan, Earthquake of March 11, Oakland, CA.

[22] Kumar, M., 2015. Seismic Isolation of Nuclear Power Plants Using Elastomeric Bearings. Thesis, (PhD). University at Buffalo, State University of New York.

[23] Buckle, I., Yen, W.-H. (.P.), Marsh, L., \&Monzon, E. (2012). Implications of bridge performance during Great East Japan Earthquake for U.S. seismic design practice. In Proceedings of the International Symposium on Engineering Lessons Learned from the 2011 Great East Japan Earthquake, March 1-4, 2012, Tokyo (pp. 1363-1374).

[24] Yang, R., Q., et al., 2010. "Tensile Stiffness and Deformation Model of Rubber Isolators in Tension and Tension-Shear States". Journal of Engineering Mechanics, Vol. 136, pp. 429-437.

[25] Tubaldi, E., Mitoulis, A., S., Ahmadi, H., Muhr, A., 2016. A parametric study on the axial behaviour of elastomeric isolators in multi-span bridges subjected to horizontal excitations. Bulletin of Earthquake Engineering, pp1-26.DOI: 10.1007/s10518-016-9876-9.

[26] Mitoulis, S., Muhr, A., Ahmadi, H., 2014. Uplift of Elastomeric Bearings in Isolated Bridges- A Possible Mechanism: Effects and Remediation. $2^{\text {nd }}$ European Conference on Earthquake Engineering and Seismology, 25-29 August 2014, Istanbul, Turkey.

[27] Kumar, M., Whittaker, A., S., Constantinou, M., C., 2015. "Response of Base-Isolated Nuclear Structures to Extreme Earthquake Shaking". Nuclear Engineering and Design, Vol. 295, pp. 860-874.

[28] Morgan, T., A., 1998. Characterization and Seismic Performance of High-Damping Rubber Isolation Bearings. Thesis, (MEng).University of California Berkeley. 
[29] Kumar, M., Whittaker, A., S., Constantinou, M., C., 2014. "An Advanced Numerical Model of Elastomeric Seismic Isolation Bearings". Earthquake Engineering \& Structural Dynamics, Vol. 43, pp. 1955-1974.

[30] Roeder, C., W., Stanton, J., F., Taylor, W., A., 1987. Performance of Elastomeric Bearings. National Cooperative Highway Research Program (NCHRP), Report 298, Washington D.C.: Transportation Research Board.

[31] Osgooei, P., M., Konstantinidis, D., Tait, M., J., 2016. "Variation of the Vertical Stiffness of Strip-Shaped Fiber-Reinforced Elastomeric Isolators under Lateral Loading". Composite Structures, Vol. 144, pp. 177-184.

[32] Van Engelen, N., C, Tait, M., J., Konstantinidis, D., 2016. "Development of Design Code Oriented Formulas for Elastomeric Bearings Including Bulk Compressibility and Reinforcement Extensibility". Journal of Engineering Mechanics, Vol. 142 (6).

[33] Stanton, J., F., Roeder, C., W., 1992. Elastomeric Bearings-Design, Construction and Materials. National Cooperative Highway Research Program (NCHRP), Report 248, Washington D.C.: Transportation Research Board.

[34] Constantinou, M., C., Kartoum, A., Kelly, J., M., 1992. "Analysis of Compression of Hollow Circular Elastomeric Bearings”. Engineering Structures, Vol. 14 (2), pp. 103-111.

[35] Bradley, L., G., Chang, C., P., Mckenna, B., G., 2001. "Rubber Modeling Using Uniaxial Test Data". Journal of Applied Polymer Science, Vol. 81, pp. 837-848.

[36] Ohsaki, M., Miyamura, T., Kohiyama, M., Yamashita, T., Yamamoto, M., Nakamura, N., 2015. "Finite-Element Analysis of Laminated Rubber Bearing of Building Frame under Seismic Excitation". Earthquake Engineering \& Structural Dynamics.

[37] Van Engelen N., C., Konstantinidis, D., Tait, M., J., 2015. „Structural and Nonstructural Performance of a Seismically Isolated Building Using Stable Unbonded Fiber-Reinforced Elastomeric Isolators". Earthquake Engineering \& Structural Dynamics, Vol. 45 (3), pp. 421439.

[38] Kelly, J., M., Konstantinidis,D., 2011. Mechanics of Rubber Bearings for Seismic and Vibration Isolation. John Wiley \& Sons, New York: U.S.A.

[39] Cardone, D., Perrone, G., 2012. "Critical Load of Slender Elastomeric Seismic Isolators: An Experimental Perspective”. Engineering Structures, Vol. 40, pp. 198-204.

[40] Ghosh, G., Singh, Y., Thakkar, S., K., 2011. "Seismic Response of a Continuous Bridge with Bearing Protection Devices”. Engineering Structures, Vol. 33, pp. 1149-1156.

[41] Gent, A., N., Lindley, P., B., 1958. "Internal Rupture of Bonded Rubber Cylinders in Tension". Proceedings of the Royal Society of London. Series A, Mathematical, Physical and Engineering Sciences, Vol. 249 (1257), pp. 195-205, The Royal Society.

[42] Mooney, M., 1940. "A Theory of Large Elastic Deformation”. Journal of Applied Physics, Vol. 11 (9), pp. 582-592.

[43] Rivlin, R., S., 1948. "Large Elastic Deformations of Isotropic Materials IV.Further Developments of the General Theory". Philosophical Transactions of the Royal Society of London, Series A: Mathematical, Physical and Engineering Sciences, Vol. 241 (835), pp. 379397, The Royal Society.

[44] Ogden, W., R., 1972.Large Deformation Isotropic Elasticity-On the Correlation of Theory and Experiment for Incompressible Rubberlike Solids. Proceedings of the Royal Society of London. Series A, Mathematical and Physical Sciences, Vol. 326(1567), pp. 565-584, The Royal Society.

[45] Iwabe, N.,Takayama, M., Kant, N., Wada, A., 2000. Experimental Study on the Effect of Tension for Rubber Bearings. Proceedings, $12^{\text {th }}$ World Conference on Earthquake Engineering.

[46] DassaultSystèmes, 2014. Computer Program ABAQUS/CAE. Providence, RI.

[47] DassaultSystèmes, 2014. ABAQUS/CAE 6.13user's Manual.Abaqus Ver. 6.13 Documentation, Providence, RI.

[48] Kumar, M., 2012. Analysis of Elastomeric Bearings in Compression- CIE 526: Finite Element Structural Analysis. Department of Civil, Structural and Environmental Engineering. Buffalo, U.S.A.: University of Buffalo.

[49] Mullins, L., 1969. "Softening of Rubber by Deformation". Rubber Chemistry and Technology, Vol. 42 (1), pp. 339-362. 
[50] Diani, J., Fayolle, B., Gilormini, P., 2009. "A review on the Mullins Effect”. European Polymer Journal, Vol. 45 (3), pp. 601-612.

[51] Bergström, J.S., Boyce, M.C., 1998. "Constitutive Modeling of the Large Strain TimeDependent Behavior of Elastomers". Journal of Mechanics Physics Solids, Vol. 46, pp. 931954.

[52] Manos, G., C., Mitoulis, S., Kourtidis, V., Sextos, V., Tegos, I., 2007. Study of the Behavior of Steel Laminated Rubber Bearings under Prescribed Loads.10th World Conference on Seismic Isolation, Energy Dissipation and Active Vibrations, Control of Structures, 28-31 May 2007, Istanbul, Turkey.

[53] Mitoulis, S., A., 2007. Bridges with Fixities and Bearings VS Isolated Systems. COMPDYN $4^{\text {th }}$ International Conference in Computational Methods in Structural Dynamics and Earthquake Engineering, 12-14 June 2013, Kos, Greece. 


\section{FIGURES}
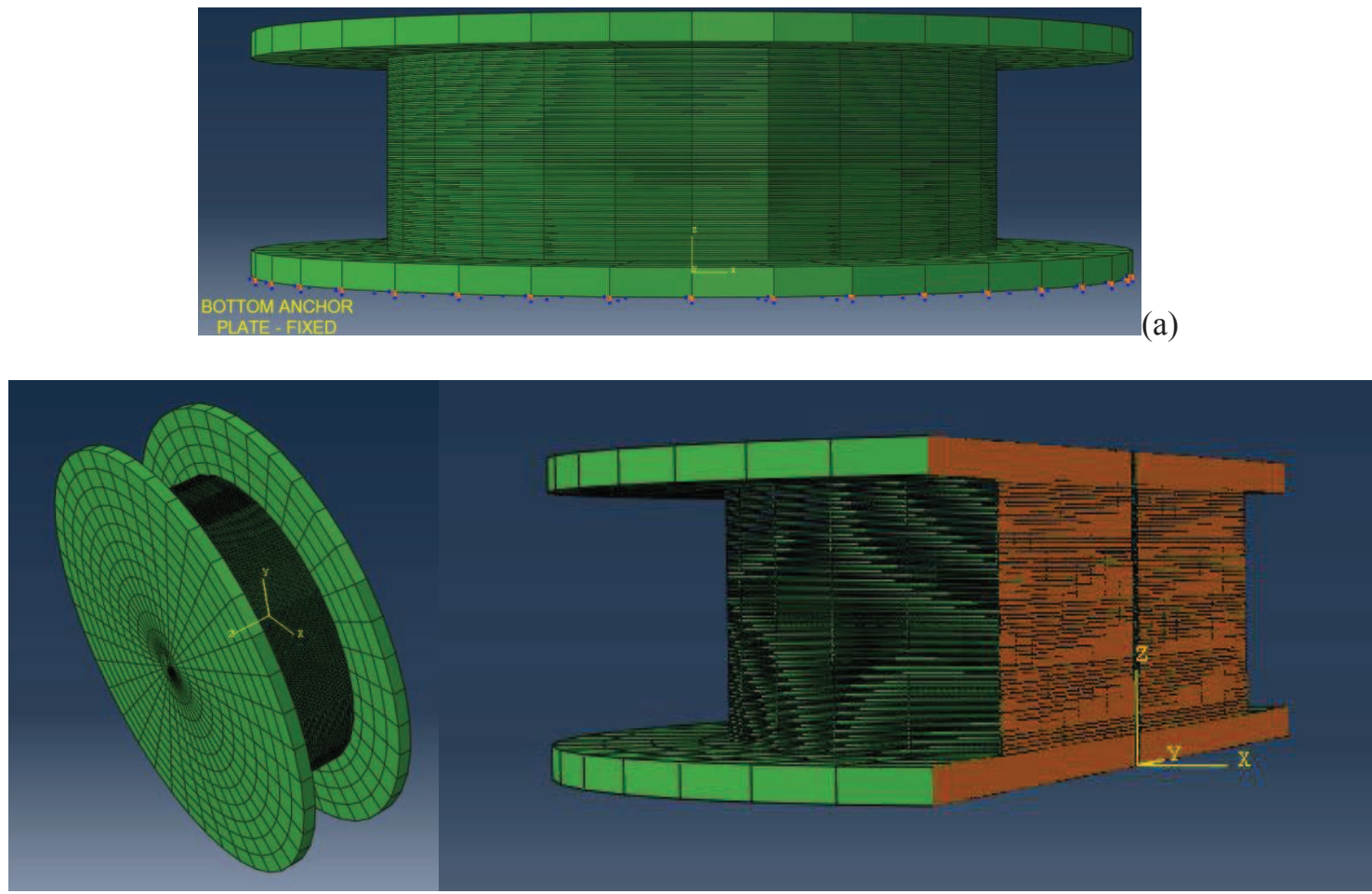

(b)

(c)

Figure 1.Meshing of the reference $\mathrm{NL}^{\mathrm{C}}$ elastomeric bearing in ABAQUS: (a) side viewand bottom anchor plate boundary conditions, (b) three dimensional model, (c) section. 


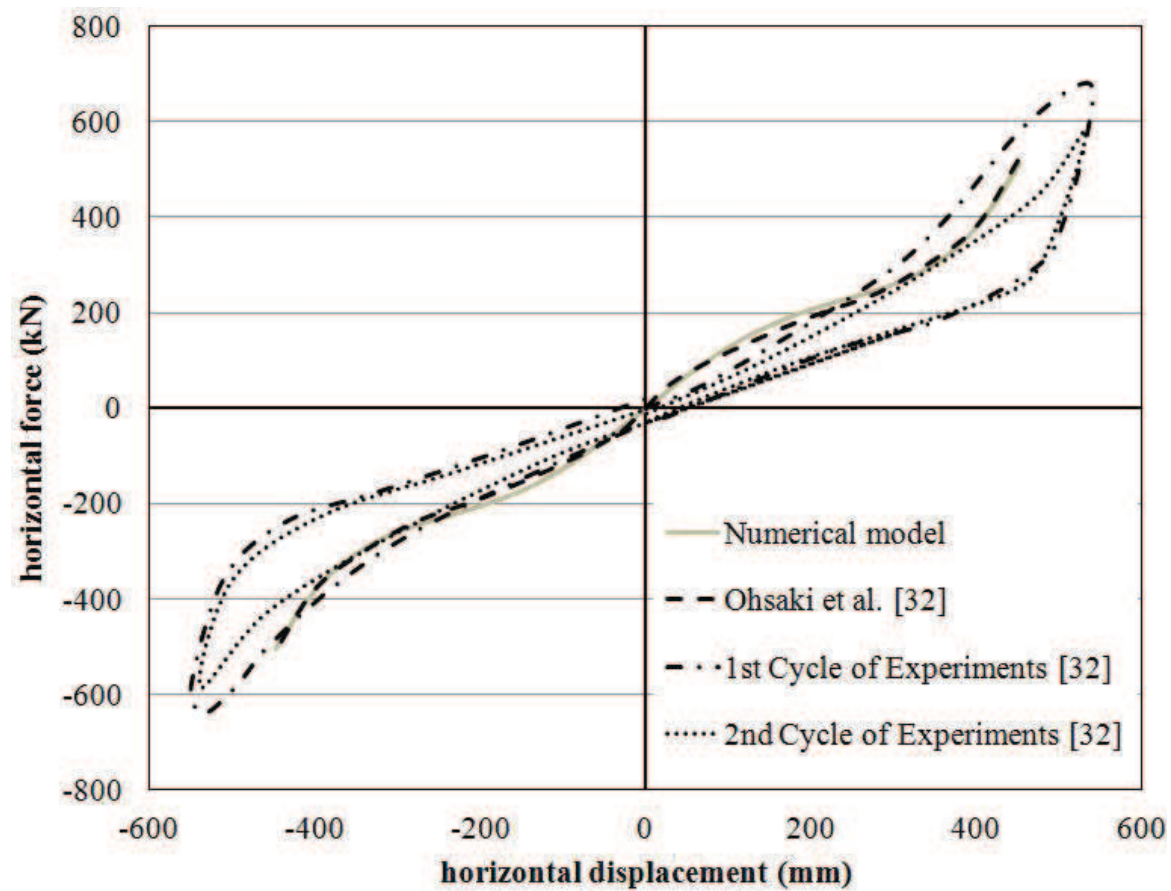

Figure 2.Validation of the reference bearing model against the available numerical and experimental results. 


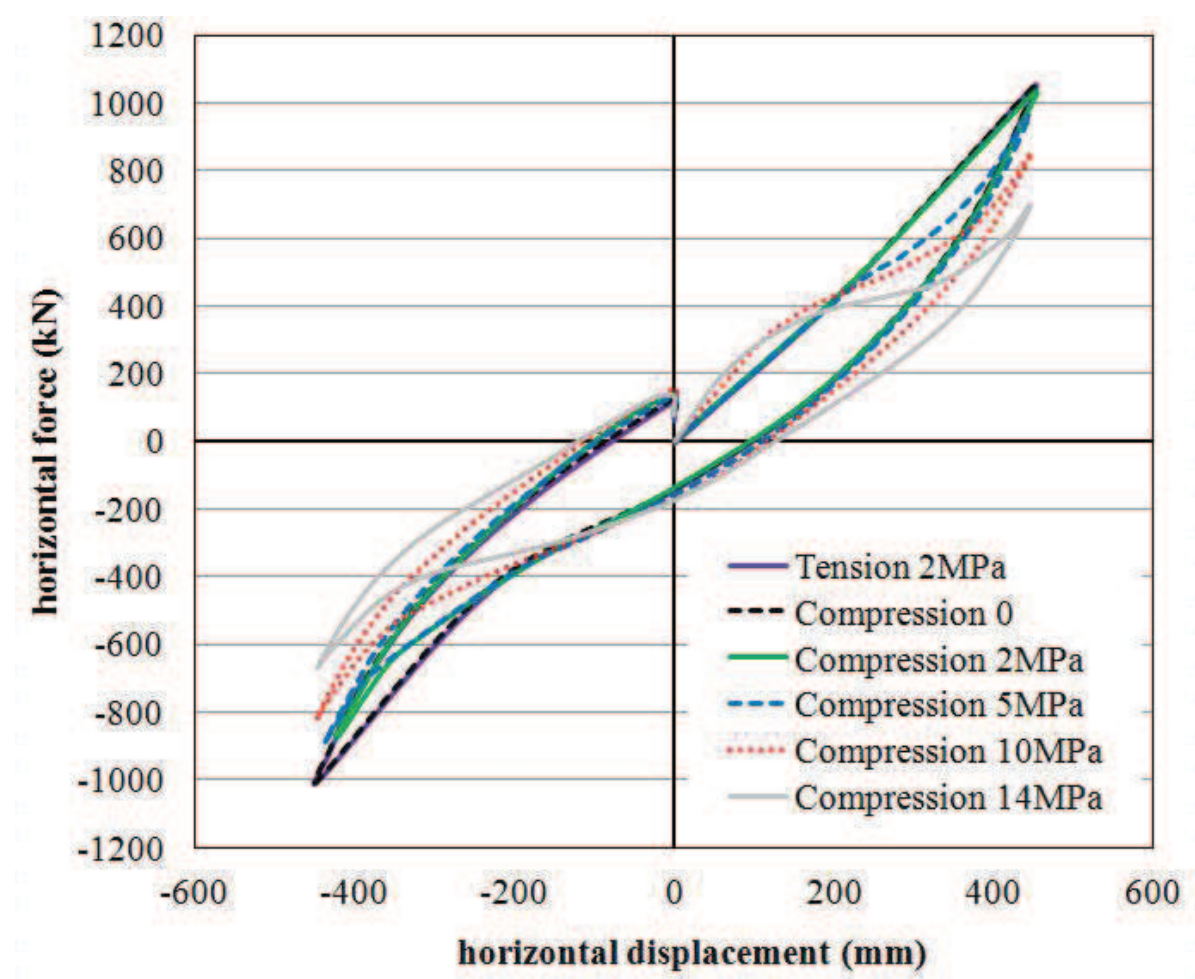

(a)

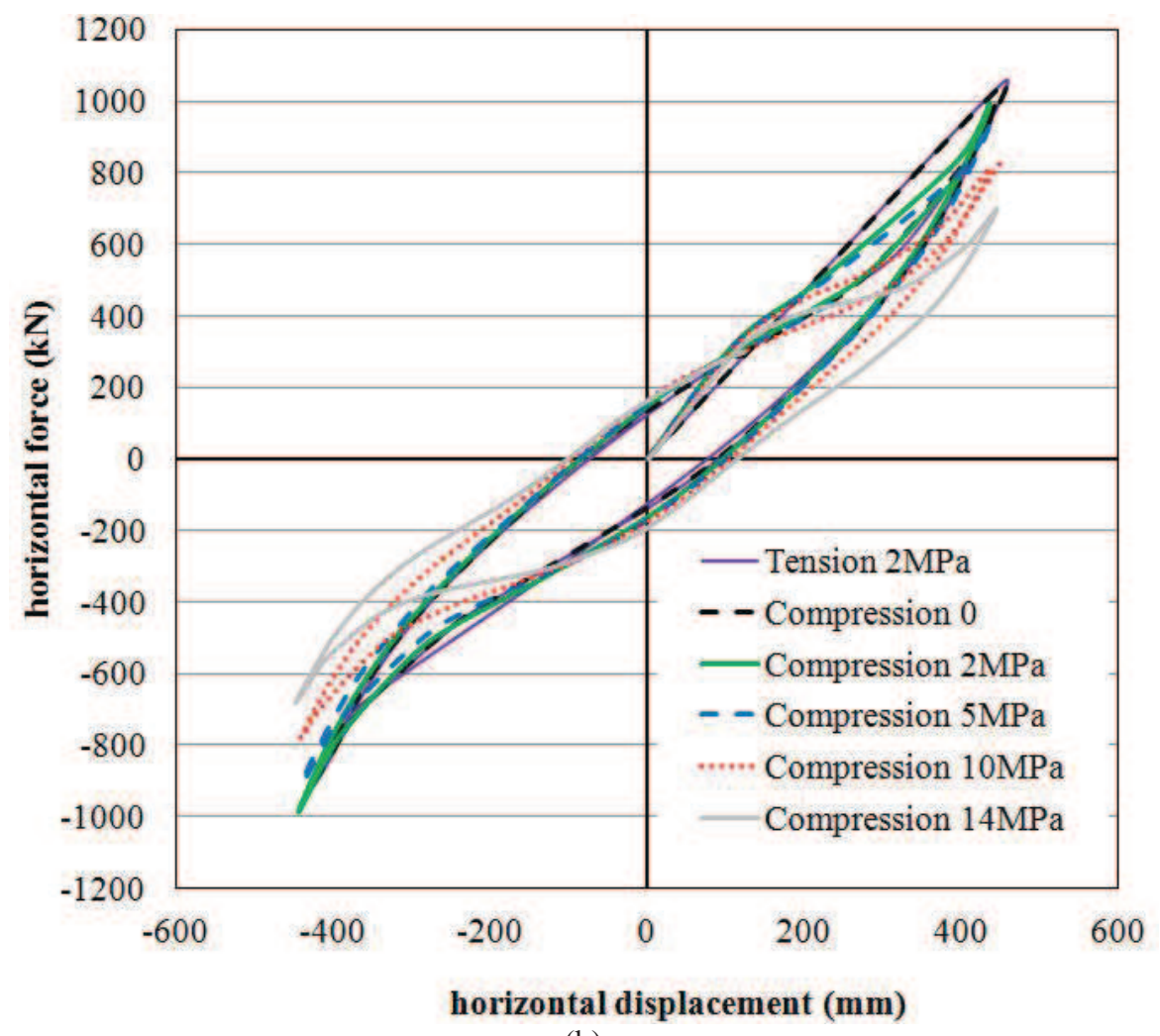

(b)

Figure 3.Response of the reference steel-laminated elastomeric bearing for variable axial loads (shear strain $375 \%$ ) for (a) one cycle of loading $\left(N L_{1} .-N L_{6}\right)$ and (b) two cycles of loading $\left(N L_{10}-N L_{15}\right)$. 


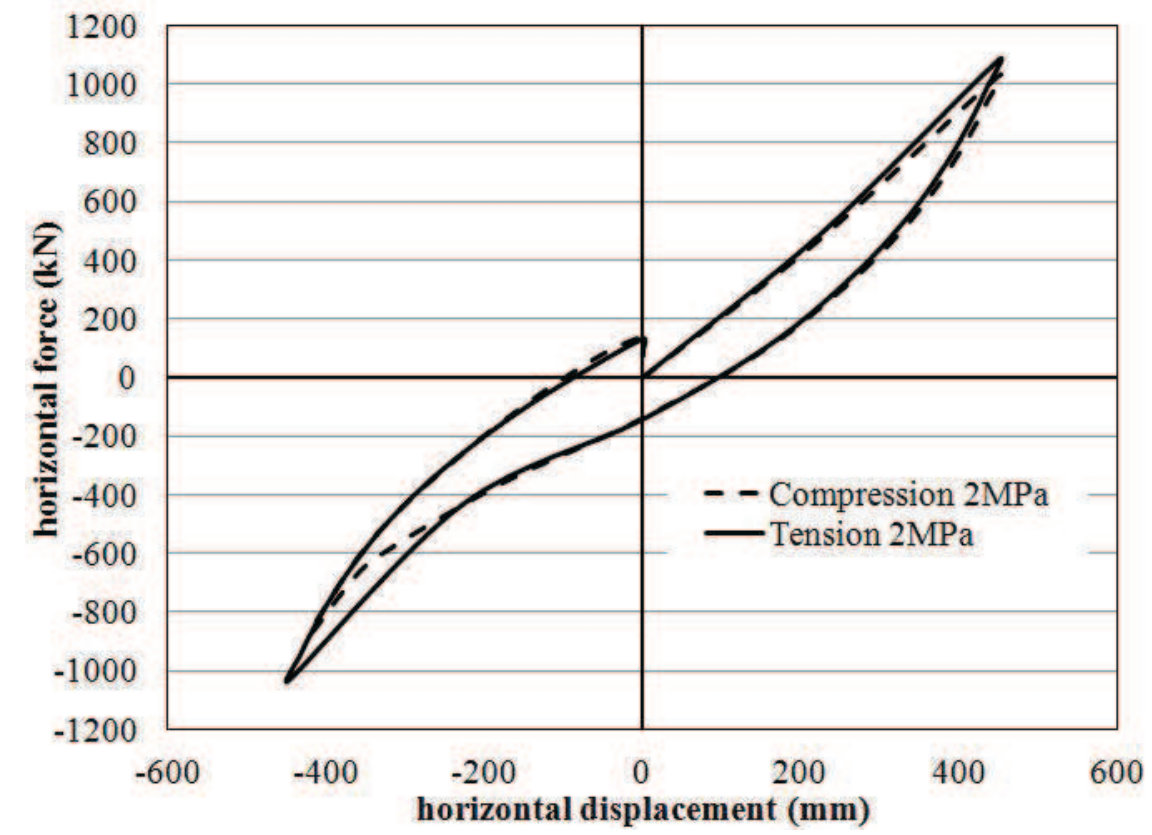

Figure 4. Shear force-displacement response of the steel-laminated elastomeric bearings for axial tension (2 MPa) and axial compression (2 MPa) (shear strain is $375 \%$ ). 


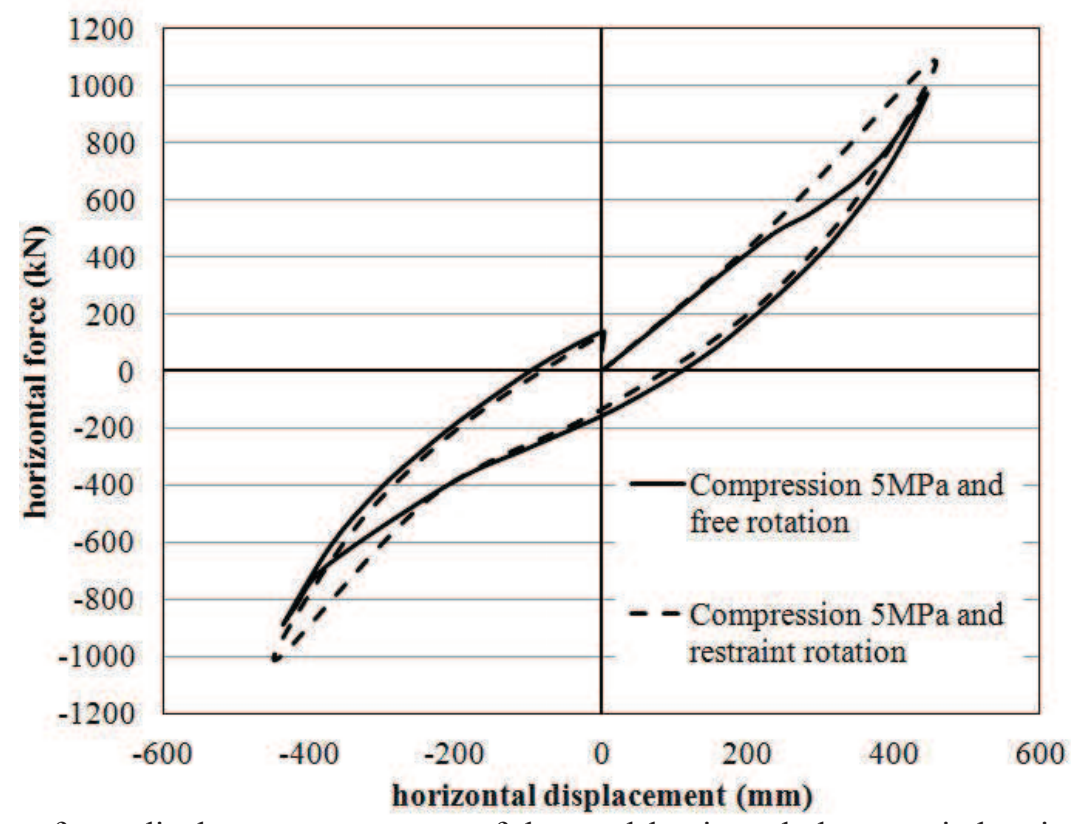

Figure 5. Shear force-displacement response of the steel-laminated elastomeric bearings for different boundary conditions (compression $5 \mathrm{MPa}$ and shear strain $375 \%$ ). 


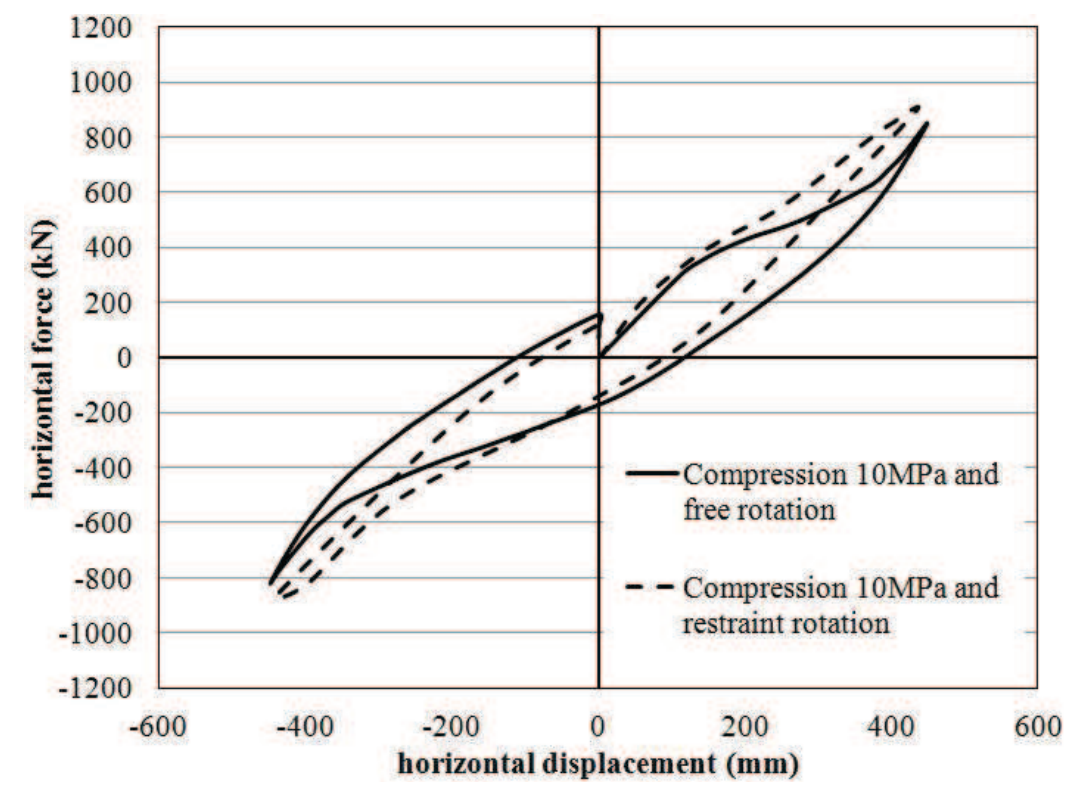

Figure 6. Shear force-displacement response of the steel-laminated elastomeric bearings for different boundary conditions (compression $10 \mathrm{MPa}$ and shear strain $375 \%$ ). 


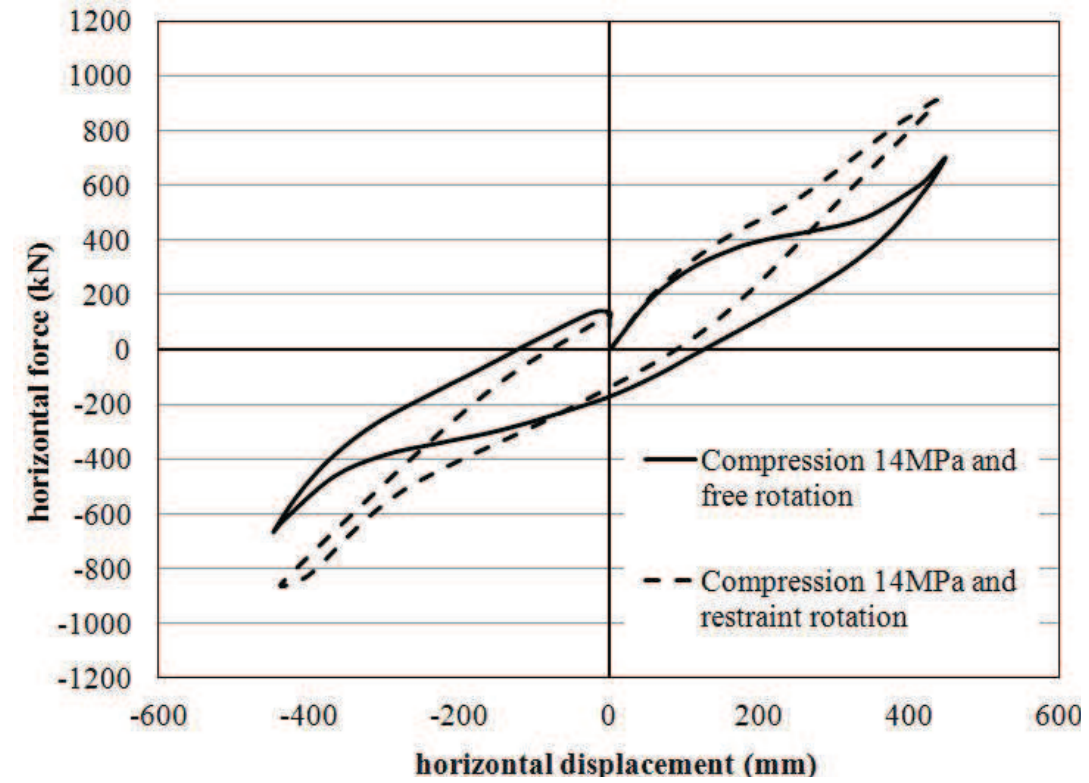

Figure7. Shear force-displacement response of the steel-laminated elastomeric bearings for different boundary conditions (compression $14 \mathrm{MPa}$ and shear strain $375 \%$ ). 


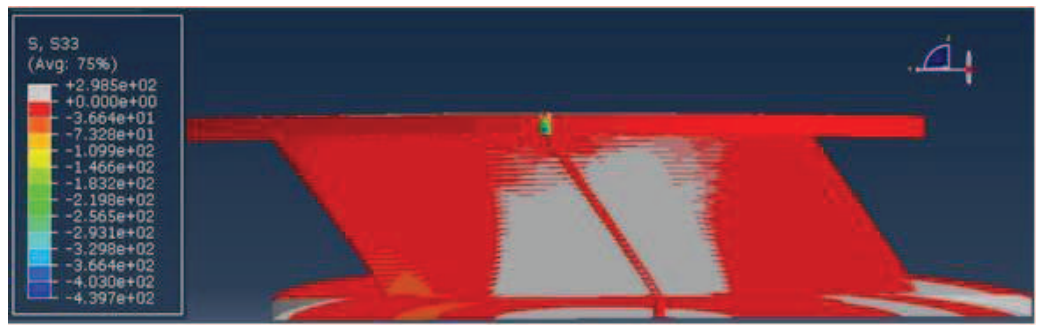

Figure 8. The axial stresses within the bearing for compressive load of $10 \mathrm{MPa}$, shear strain $125 \%$ and upper layer of the reference bearing free to rotate $\left(N L_{16}\right)$ (vertical section at bearing diameter). 


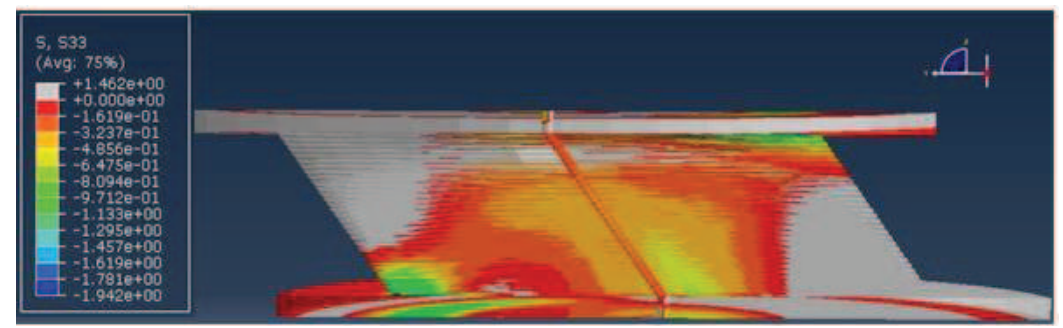

Figure 9. The axial stresses within the bearing for compressive load of $10 \mathrm{MPa}$, shear strain $125 \%$ and application of rotational restraint of the upper layer of the reference bearing $\left(N L_{17}\right)$ (vertical section at bearing diameter). 


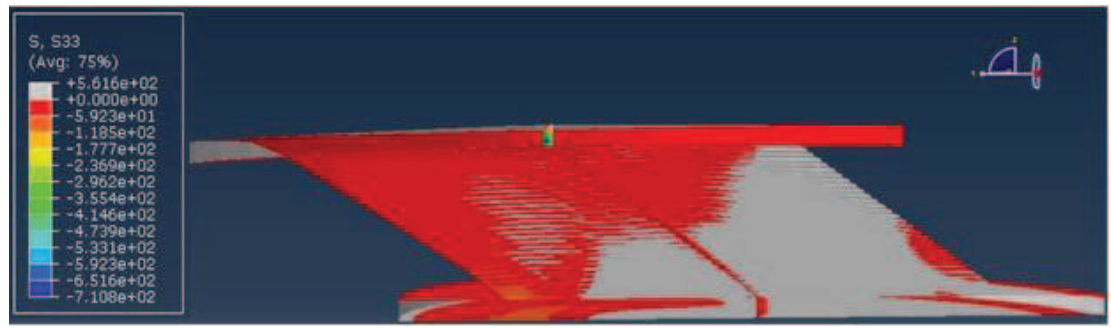

Figure 10. The axial stresses within the bearing for compressive load of $10 \mathrm{MPa}$, shear strain $250 \%$ and upper layer of the reference bearing free to rotate $\left(N L_{18}\right)$ (vertical section at bearing diameter). 


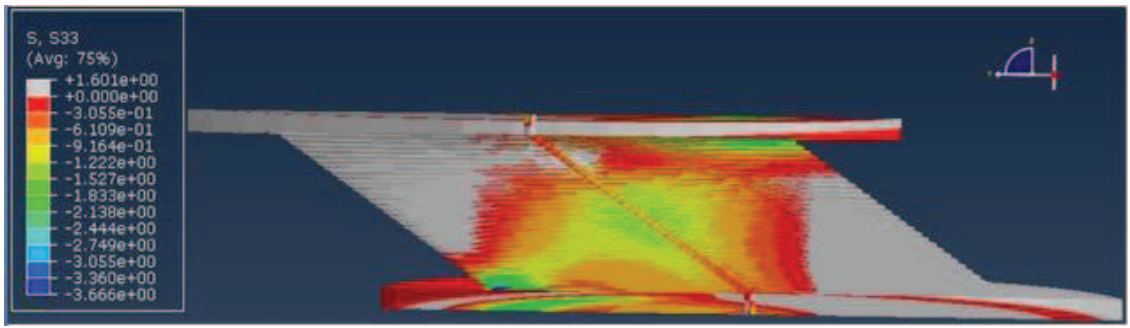

Figure 11. The axial stresses within the bearing for compressive load of $10 \mathrm{MPa}$, shear strain $250 \%$ and application of rotational restraint of the upper layer of the reference bearing $\left(N L_{19}\right)$ (vertical section at bearing diameter). 


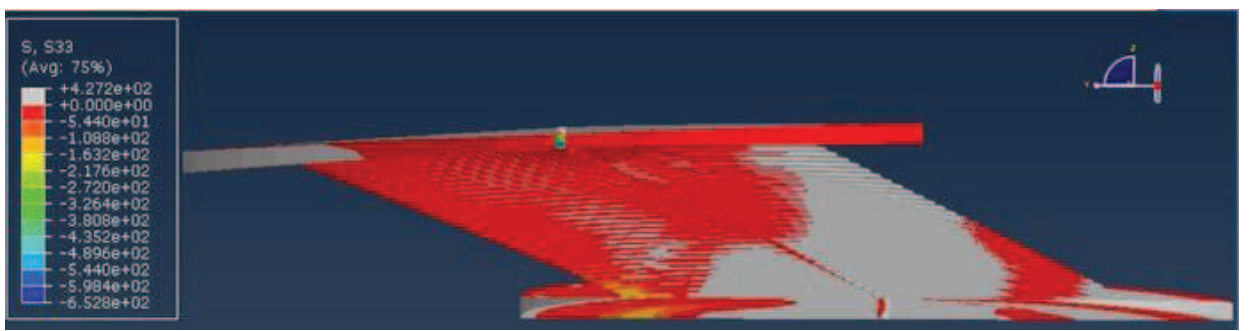

Figure 12. The axial stresses within the bearing for compressive load of $10 \mathrm{MPa}$, shear strain $375 \%$ and upper layer of the reference bearing free to rotate $\left(N L_{20}\right)$ (vertical section at bearing diameter). 


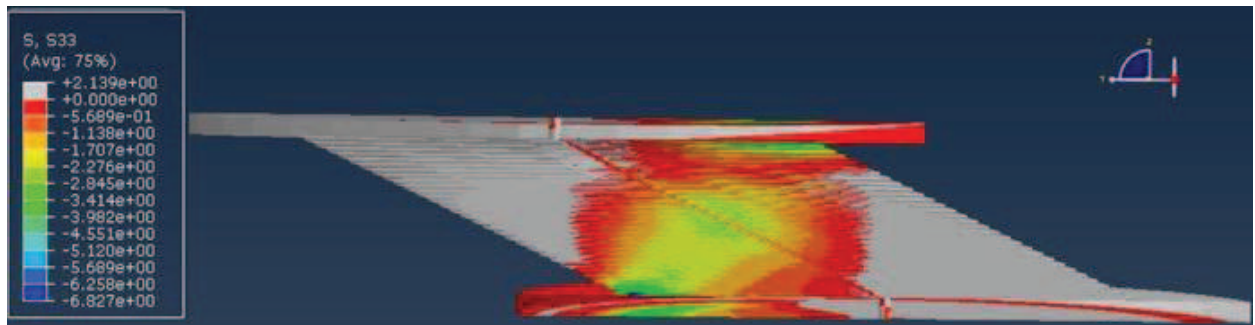

Figure 13. The axial stresses within the bearing for compressive load of $10 \mathrm{MPa}$, shear strain $375 \%$ and application of rotational restraint of the upper layer of the reference bearing $\left(N L_{21}\right)$ (vertical section at bearing diameter). 


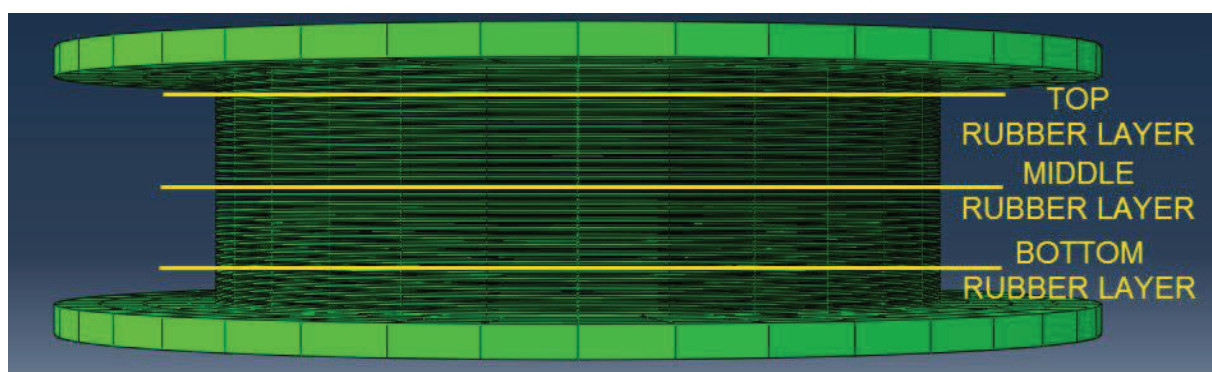

Figure 14. Three-dimensional view of the bearing indicating the position of the rubber layersshown in figures 15 and 16 below. 


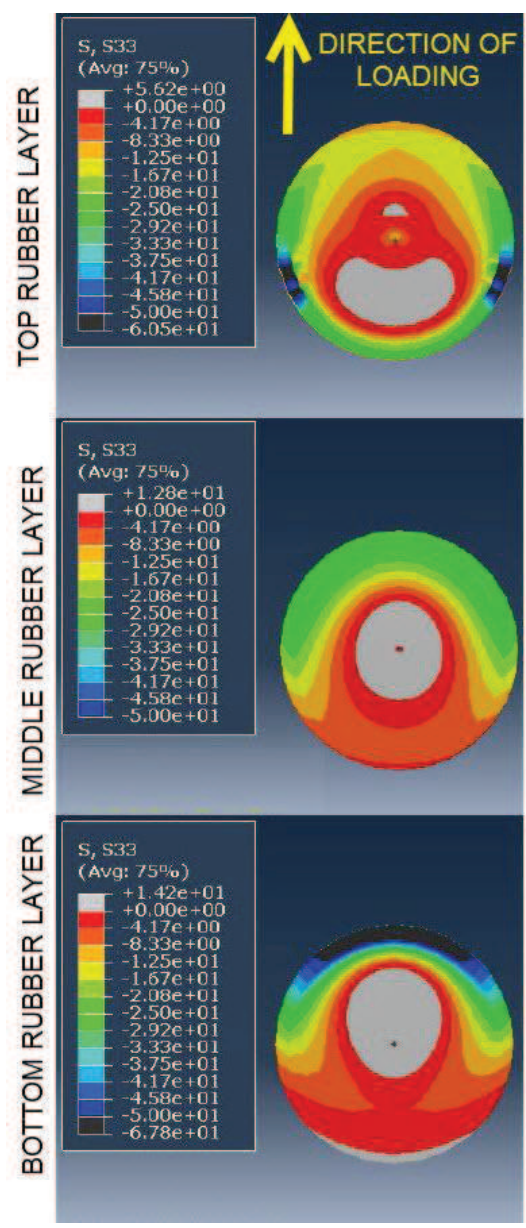

(a)

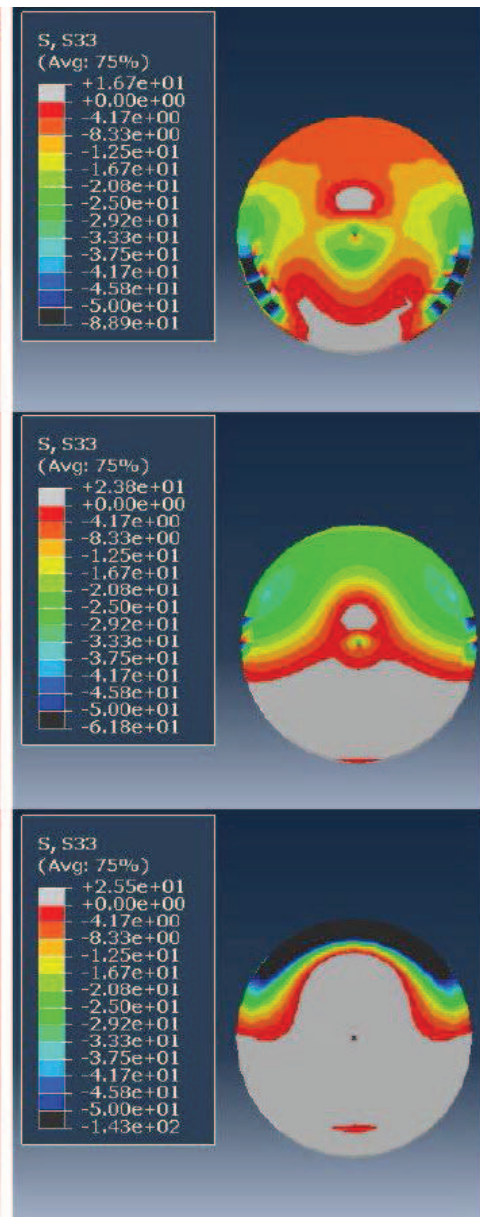

(b)

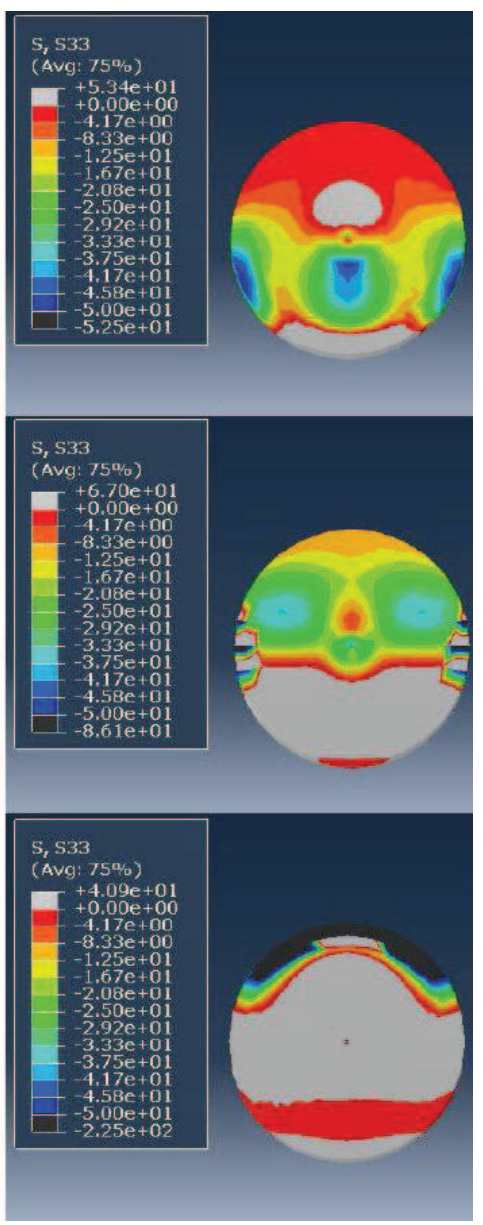

(c)

Figure 15. Axial stresses of the bearings at horizontal sections at the top, middle and bottomrubber layer. Gray areas indicate tensile stresses. Compressive load $10 \mathrm{MPa}$ and upper layer of the reference bearing free to rotate, shear strain: (a) $125 \%\left(N L_{16}\right)$, (b) $250 \%\left(N L_{18}\right)$, (c) $375 \%\left(N L_{20}\right)$. 


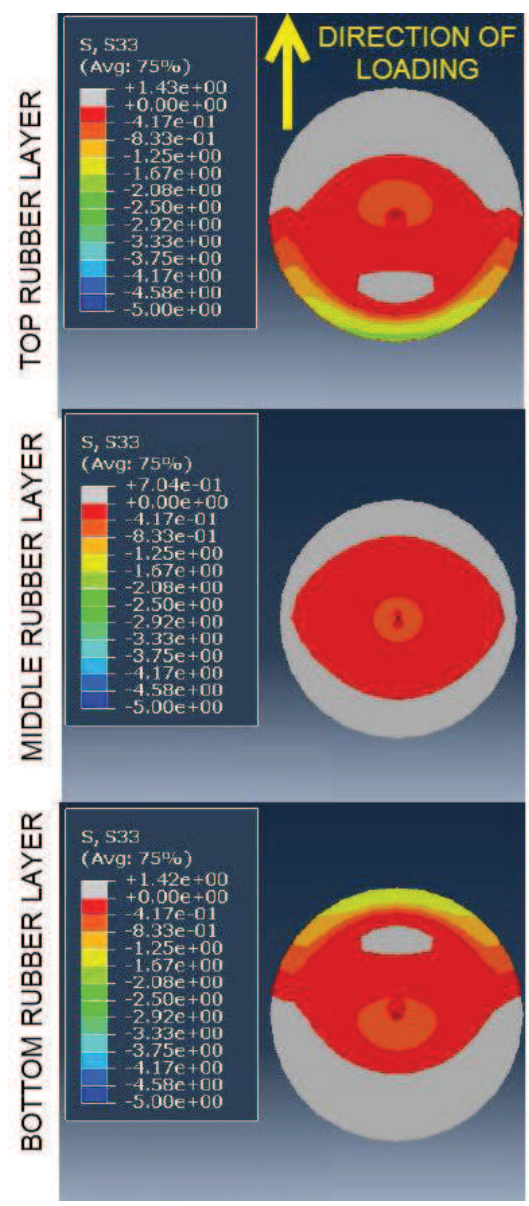

(a)

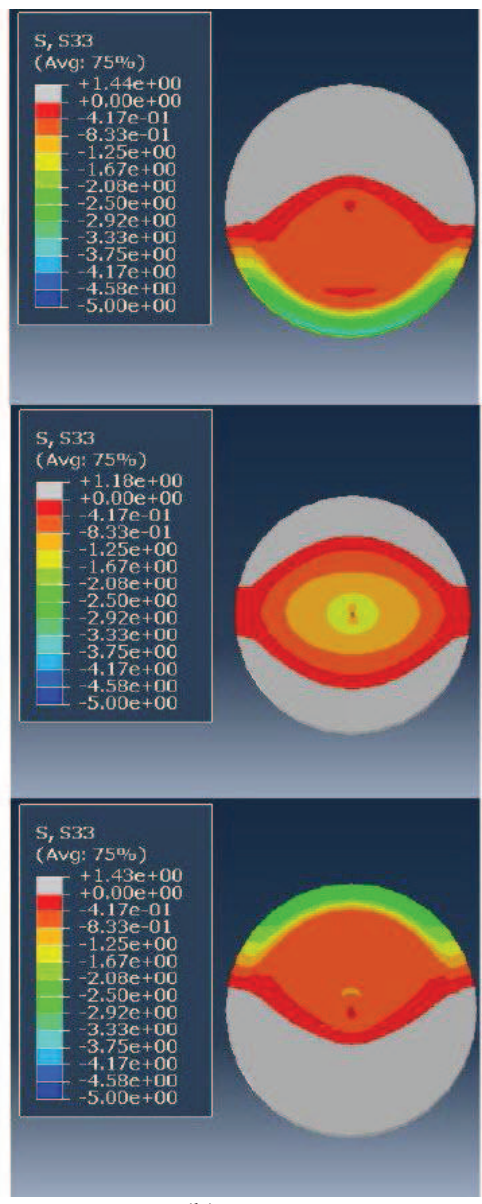

(b)

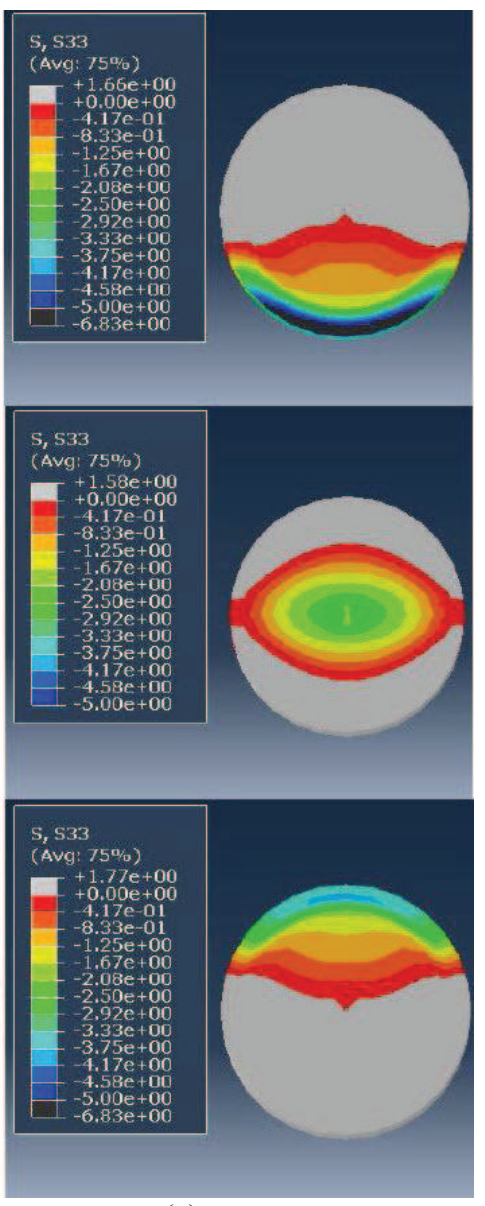

(c)

Figure 16. Axial stresses of the bearings at horizontal sections at the top, middle and bottomrubber layer.Gray areas indicate tensile stresses. Compressive load of $10 \mathrm{MPa}$, application of rotational restraint of the upper layer, shear strain: (a) $125 \%\left(N L_{17}\right)$, (b) $250 \%\left(N L_{19}\right)$, (c) $375 \%\left(N L_{21}\right)$. 


\section{TABLES}

Table 1.Geometry of the reference bearing $N L^{C}$.

\begin{tabular}{lll}
\hline & notation (unit) & value \\
\hline diameter of the elastomer & $\mathrm{D}_{\mathrm{r}}(\mathrm{mm})$ & 700 \\
\hline diameter of the anchor plate & $\mathrm{D}_{\mathrm{AP}}(\mathrm{mm})$ & 1000 \\
\hline diameter of the hole & $\mathrm{D}_{\mathrm{h}}(\mathrm{mm})$ & 15 \\
\hline area of the elastomer layer & $\mathrm{A}_{\mathrm{b}}\left(\mathrm{mm}^{2}\right)$ & 384845 \\
\hline total height of the bearing & $\mathrm{T}(\mathrm{mm})$ & 265.9 \\
\hline elastomer layer thickness & $\mathrm{t}_{\mathrm{r}}(\mathrm{mm})$ & 4 \\
\hline number of elastomeric layers & $\mathrm{n}_{\mathrm{r}}$ & 30 \\
\hline total elastomer thickness & $\mathrm{T}_{\mathrm{r}}(\mathrm{mm})$ & 120 \\
\hline single steel shim thickness & $\mathrm{t}_{\mathrm{s}}(\mathrm{mm})$ & 3.1 \\
\hline number of steel shims & $\mathrm{n}_{\mathrm{s}}$ & 29 \\
\hline total steel shim thickness & $\mathrm{T}_{\mathrm{s}}(\mathrm{mm})$ & 89.9 \\
\hline single anchor plate thickness & $\mathrm{t}_{\mathrm{AP}}(\mathrm{mm})$ & 28 \\
\hline number of anchor plates & $\mathrm{n}_{\mathrm{AP}}$ & 2 \\
\hline total anchor plate thickness & $\mathrm{T}_{\mathrm{AP}}(\mathrm{mm})$ & 56 \\
\hline
\end{tabular}


Table 2.Analyses of the reference bearing for variable axial loads, different boundary conditions, shear strain $375 \%$ and different number of cycles of loading - unloading.

\begin{tabular}{|c|c|c|c|}
\hline No\# & $\begin{array}{l}\text { axial load } \\
(\mathrm{MPa})\end{array}$ & $\begin{array}{l}\text { restraint rotation of the } \\
\text { top anchor plate }\end{array}$ & $\begin{array}{c}\text { cycles of loading - } \\
\text { unloading }\end{array}$ \\
\hline$N L_{1}$ & 2 & No & 1 \\
\hline$N L_{2}$ & 0 & No & 1 \\
\hline $\mathrm{NL}_{3}$ & -2 & No & 1 \\
\hline $\mathrm{NL}_{4}$ & -5 & No & 1 \\
\hline$N L_{5}$ & -10 & No & 1 \\
\hline$N L_{6}$ & -14 & No & 1 \\
\hline$N L_{7}$ & -5 & Yes & 1 \\
\hline$N L_{8}$ & -10 & Yes & 1 \\
\hline$N L_{9}$ & -14 & Yes & 1 \\
\hline$N L_{10}$ & 2 & No & 2 \\
\hline$N L_{11}$ & 0 & No & 2 \\
\hline$N L_{12}$ & -2 & No & 2 \\
\hline$N L_{13}$ & -5 & No & 2 \\
\hline$N L_{14}$ & -10 & No & 2 \\
\hline$N L_{15}$ & -14 & No & 2 \\
\hline
\end{tabular}

*NL: Non-Linear bearing model 
Table 3.Analyses of the reference bearing for variable shear strains and boundary conditions (axial compressive load $10 \mathrm{MPa}$ ).

\begin{tabular}{lcc} 
No\# & shearstrain/ displacement(mm) & upper anchor plate restraint? \\
\hline$N L_{16}$ & $125 \% / 150$ & No \\
\hline$N L_{17}$ & $125 \% / 150$ & Yes \\
\hline$N L_{18}$ & $250 \% / 300$ & No \\
\hline$N L_{19}$ & $250 \% / 300$ & Yes \\
\hline$N L_{20}$ & $375 \% / 450$ & No \\
\hline$N L_{21}$ & $375 \% / 450$ & Yes \\
\hline
\end{tabular}




\section{TABLES}

Table 1.Geometry of the reference bearing $N L^{C}$.

\begin{tabular}{lll}
\hline & notation (unit) & value \\
\hline diameter of the elastomer & $\mathrm{D}_{\mathrm{r}}(\mathrm{mm})$ & 700 \\
\hline diameter of the anchor plate & $\mathrm{D}_{\mathrm{AP}}(\mathrm{mm})$ & 1000 \\
\hline diameter of the hole & $\mathrm{D}_{\mathrm{h}}(\mathrm{mm})$ & 15 \\
\hline area of the elastomer layer & $\mathrm{A}_{\mathrm{b}}\left(\mathrm{mm}^{2}\right)$ & 384845 \\
\hline total height of the bearing & $\mathrm{T}(\mathrm{mm})$ & 265.9 \\
\hline elastomer layer thickness & $\mathrm{t}_{\mathrm{r}}(\mathrm{mm})$ & 4 \\
\hline number of elastomeric layers & $\mathrm{n}_{\mathrm{r}}$ & 30 \\
\hline total elastomer thickness & $\mathrm{T}_{\mathrm{r}}(\mathrm{mm})$ & 120 \\
\hline single steel shim thickness & $\mathrm{t}_{\mathrm{s}}(\mathrm{mm})$ & 3.1 \\
\hline number of steel shims & $\mathrm{n}_{\mathrm{s}}$ & 29 \\
\hline total steel shim thickness & $\mathrm{T}_{\mathrm{s}}(\mathrm{mm})$ & 89.9 \\
\hline single anchor plate thickness & $\mathrm{t}_{\mathrm{AP}}(\mathrm{mm})$ & 28 \\
\hline number of anchor plates & $\mathrm{n}_{\mathrm{AP}}$ & 2 \\
\hline total anchor plate thickness & $\mathrm{T}_{\mathrm{AP}}(\mathrm{mm})$ & 56 \\
\hline
\end{tabular}


Table 2.Analyses of the reference bearing for variable axial loads, different boundary conditions, shear strain $375 \%$ and different number of cycles of loading - unloading.

\begin{tabular}{|c|c|c|c|}
\hline No\# & $\begin{array}{l}\text { axial load } \\
(\mathrm{MPa})\end{array}$ & $\begin{array}{l}\text { restraint rotation of the } \\
\text { top anchor plate }\end{array}$ & $\begin{array}{l}\text { cycles of loading - } \\
\text { unloading }\end{array}$ \\
\hline$N L_{1}$ & 2 & No & 1 \\
\hline $\mathrm{NL}_{2}$ & 0 & No & 1 \\
\hline $\mathrm{NL}_{3}$ & -2 & No & 1 \\
\hline$N L_{4}$ & -5 & No & 1 \\
\hline$N L_{5}$ & -10 & No & 1 \\
\hline$N L_{6}$ & -14 & No & 1 \\
\hline $\mathrm{NL}_{7}$ & -5 & Yes & 1 \\
\hline$N L_{8}$ & -10 & Yes & 1 \\
\hline$N L_{9}$ & -14 & Yes & 1 \\
\hline$N L_{10}$ & 2 & No & 2 \\
\hline$N L_{11}$ & 0 & No & 2 \\
\hline$N L_{12}$ & -2 & No & 2 \\
\hline$N L_{13}$ & -5 & No & 2 \\
\hline$N L_{14}$ & -10 & No & 2 \\
\hline$N L_{15}$ & -14 & No & 2 \\
\hline
\end{tabular}

*NL: Non-Linear bearing model 
Table 3.Analyses of the reference bearing for variable shear strains and boundary conditions (axial compressive load $10 \mathrm{MPa}$ ).

\begin{tabular}{lcc}
\hline No\# & shear strain/ displacement(mm) & upper anchor plate restraint? \\
\hline$N L_{16}$ & $125 \% / 150$ & No \\
\hline$N L_{17}$ & $125 \% / 150$ & Yes \\
\hline$N L_{18}$ & $250 \% / 300$ & No \\
\hline$N L_{19}$ & $250 \% / 300$ & Yes \\
\hline$N L_{20}$ & $375 \% / 450$ & No \\
\hline$N L_{21}$ & $375 \% / 450$ & Yes \\
\hline
\end{tabular}




\section{FIGURES}
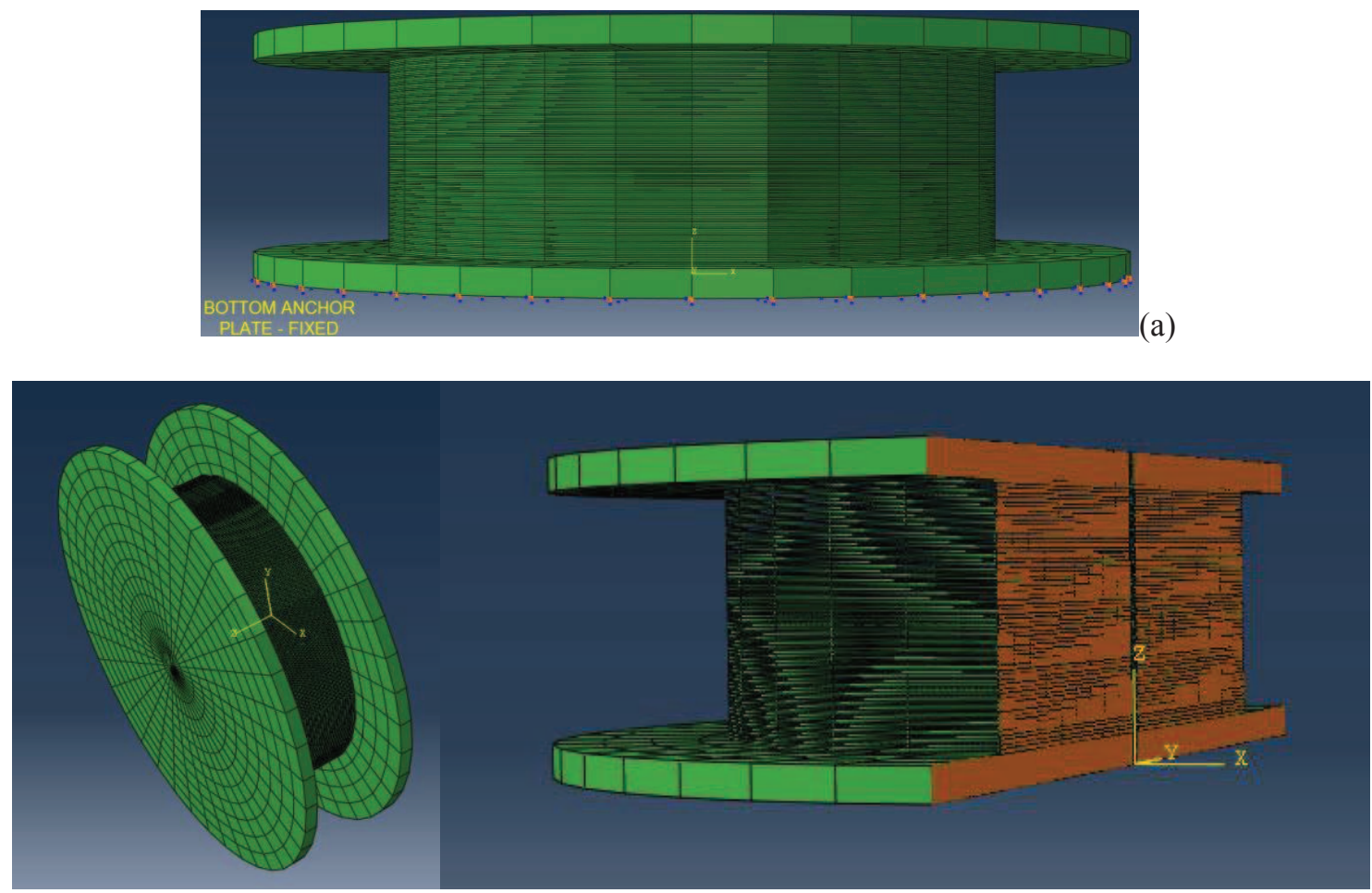

(b)

(c)

Figure 1.Meshing of the reference $\mathrm{NL}^{\mathrm{C}}$ elastomeric bearing in ABAQUS: (a) side view and bottom anchor plate boundary conditions, (b) three dimensional model, (c) section. 


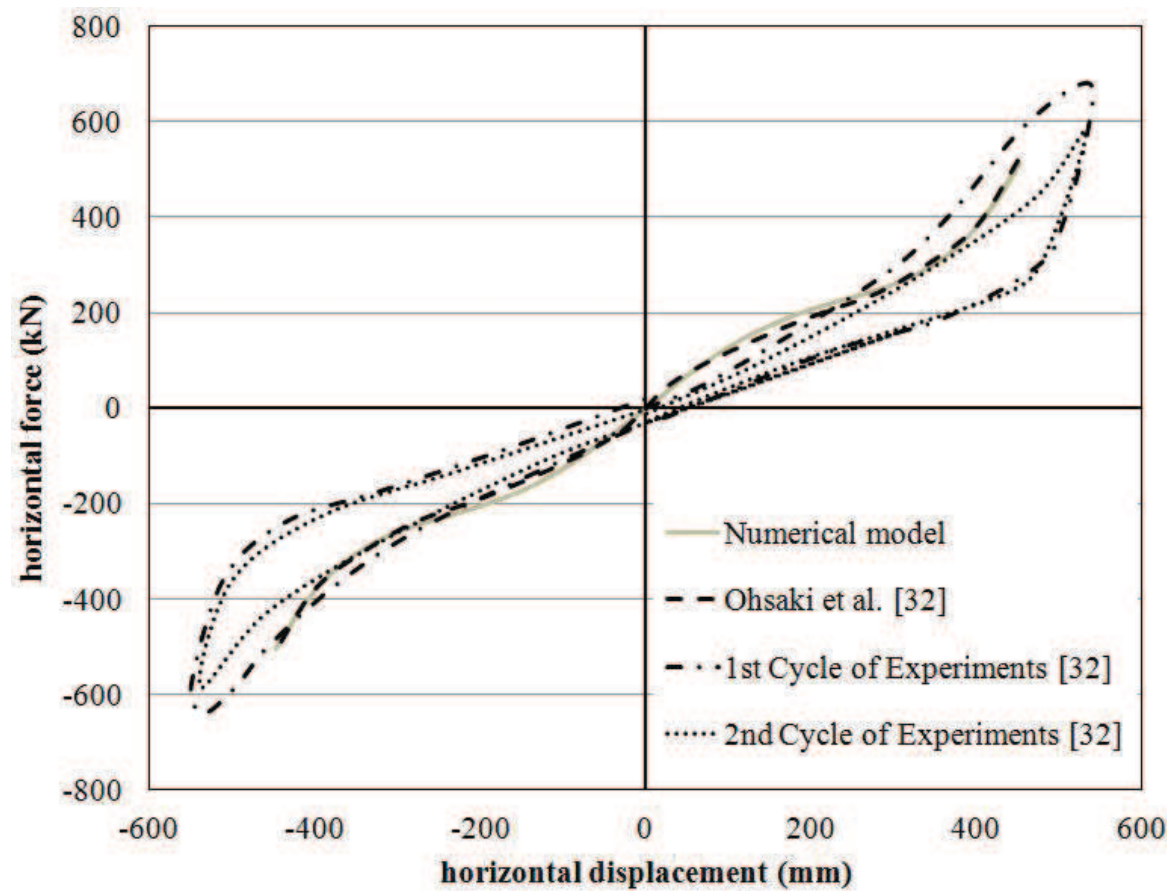

Figure 2.Validation of the reference bearing model against the available numerical and experimental results. 


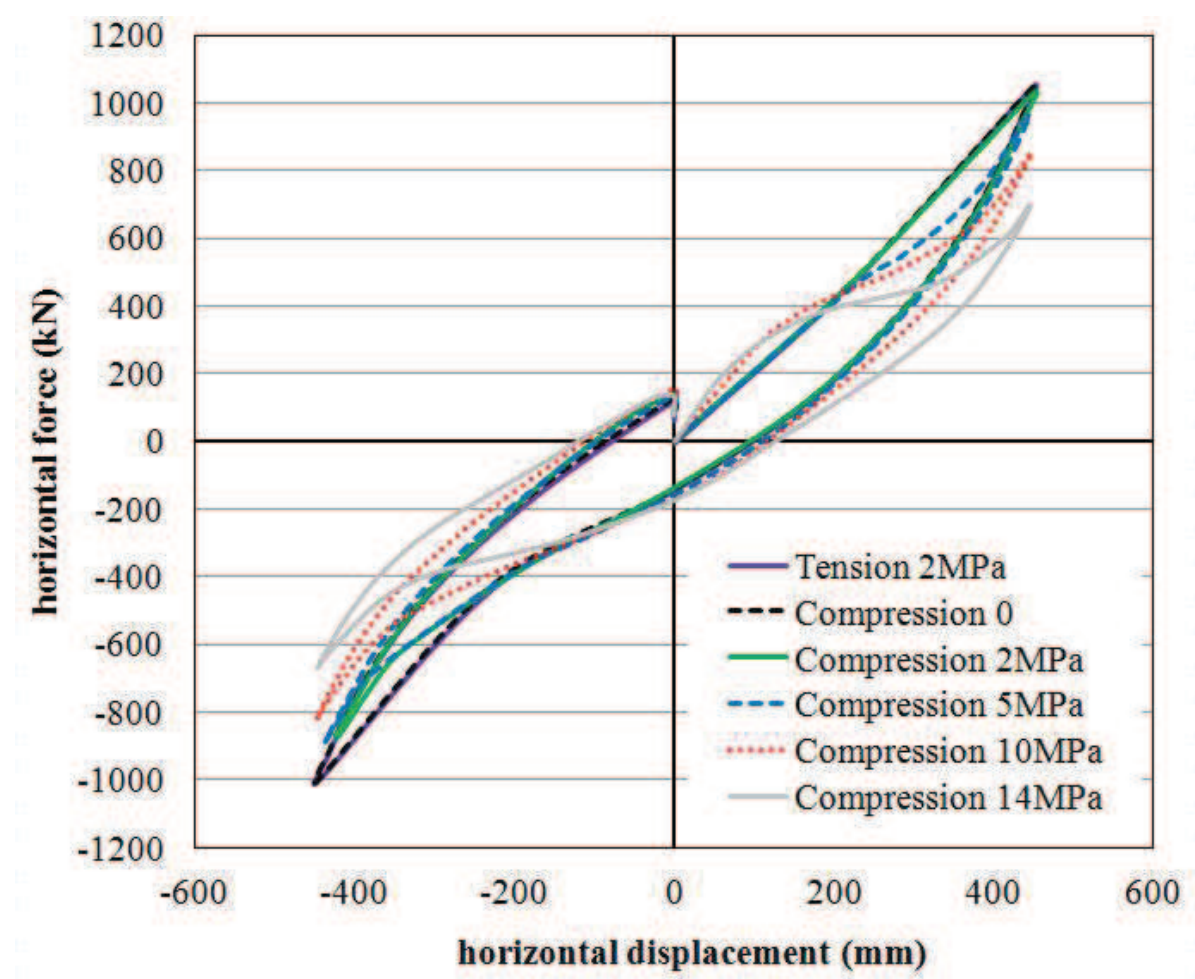

(a)

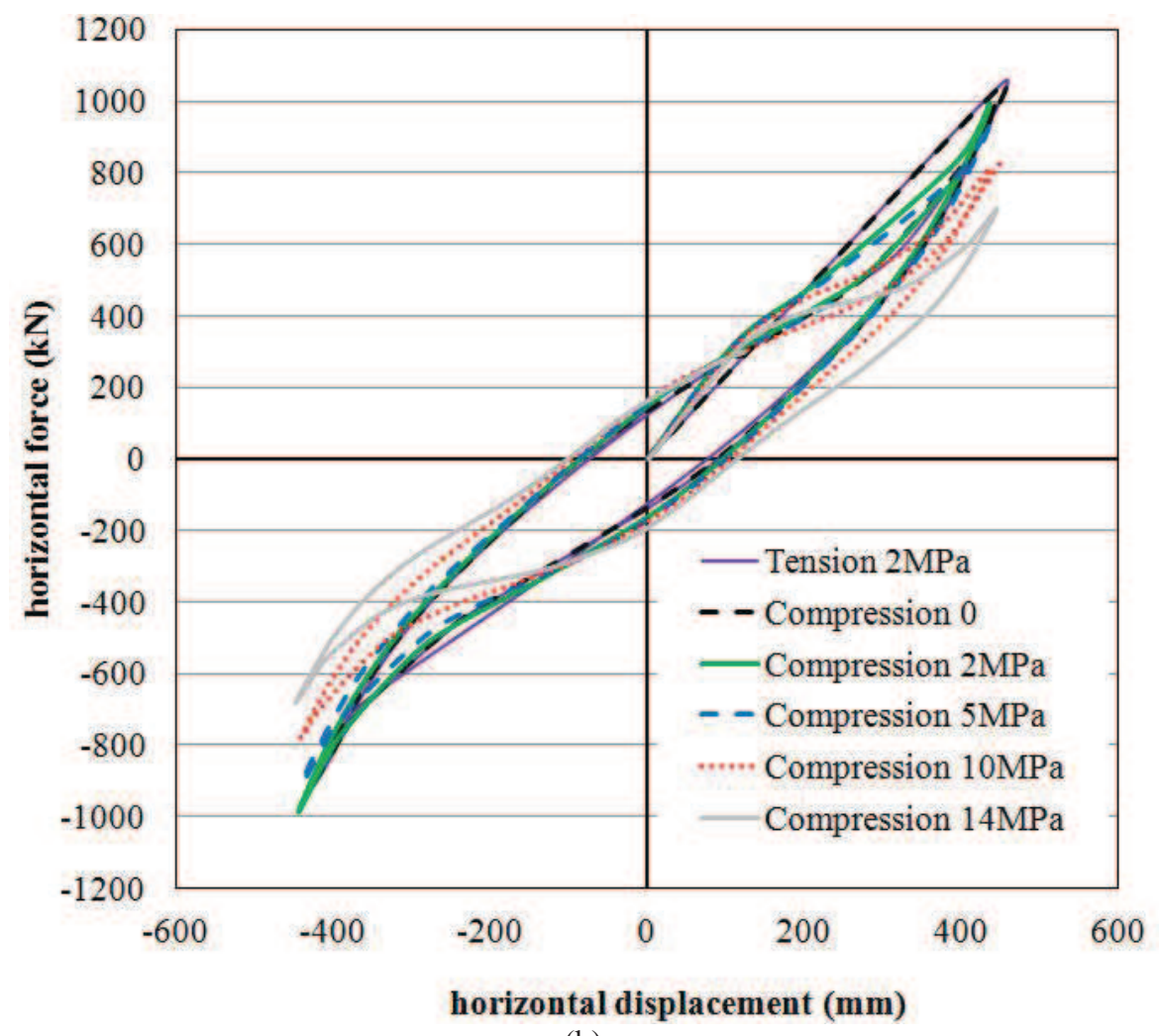

(b)

Figure 3.Response of the reference steel-laminated elastomeric bearing for variable axial loads (shear strain375\%) for (a) one cycle of loading $\left(N L_{1} .-N L_{6}\right)$ and (b) two cycles of loading $\left(N L_{10}-N L_{15}\right)$. 


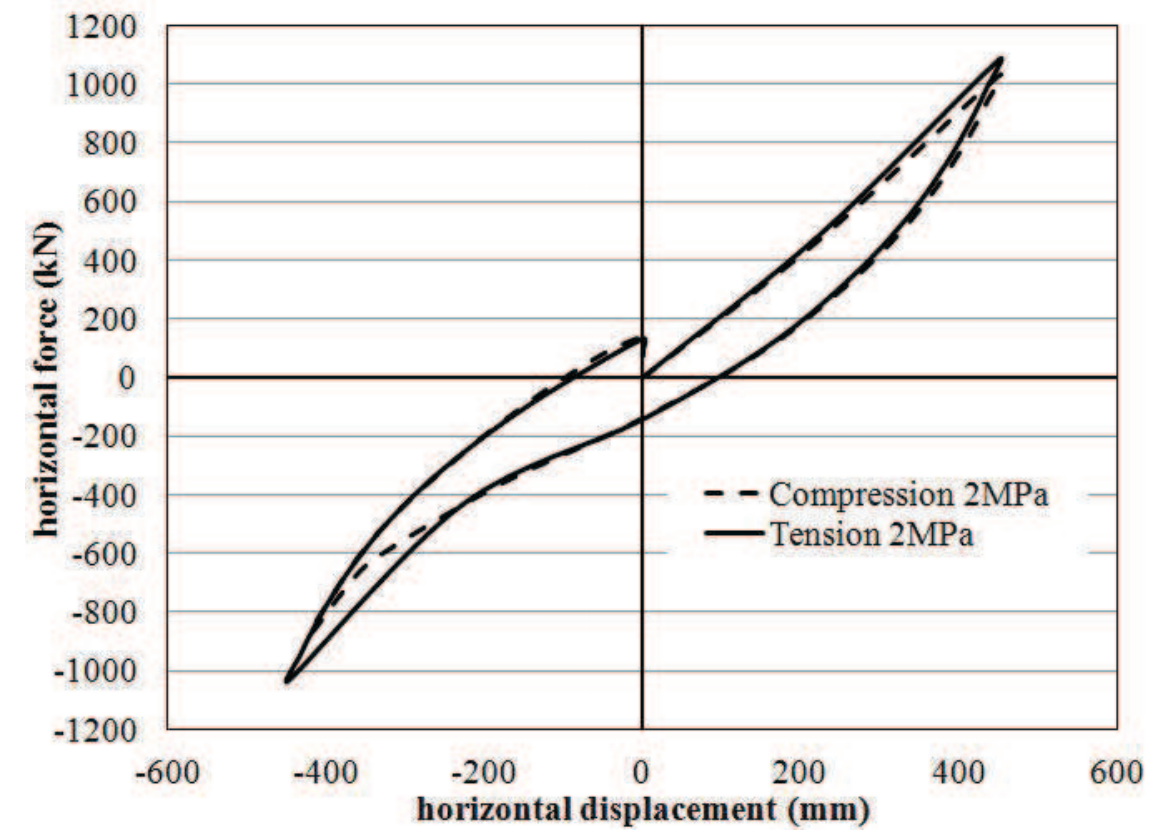

Figure 4. Shear force-displacement response of the steel-laminated elastomeric bearings for axial tension (2 MPa) and axial compression (2 MPa) (shear strain is $375 \%$ ). 


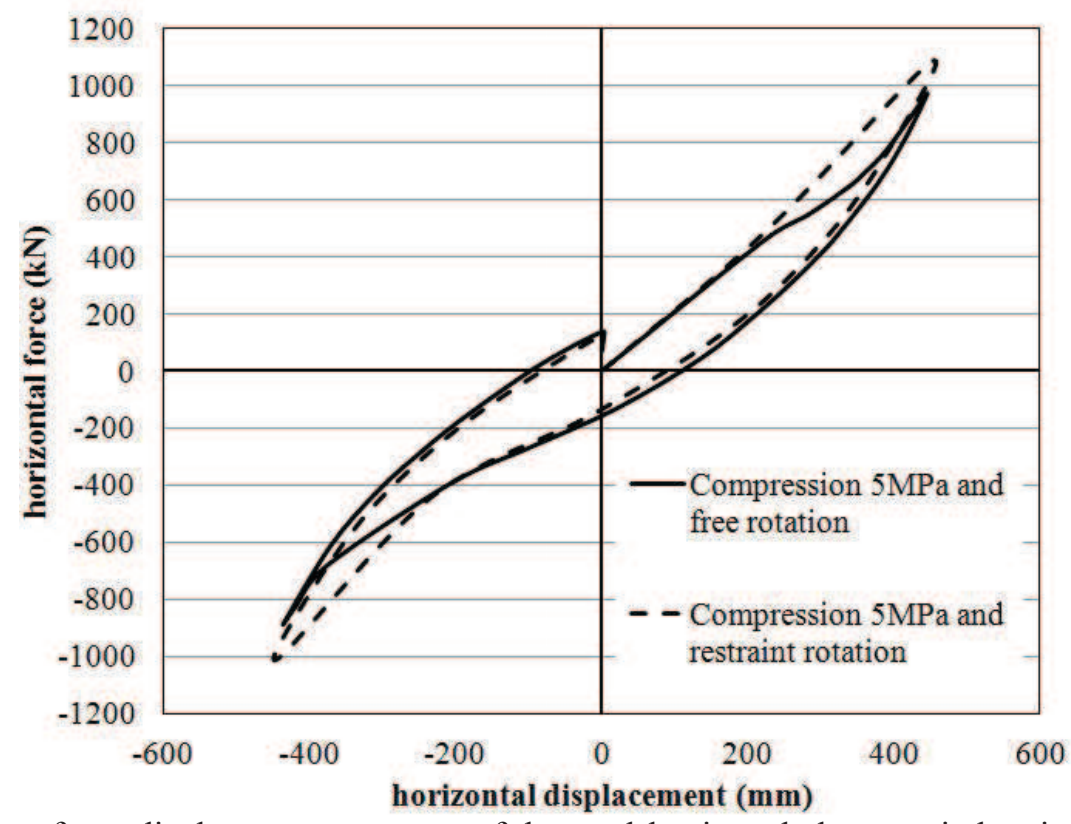

Figure 5. Shear force-displacement response of the steel-laminated elastomeric bearings for different boundary conditions (compression $5 \mathrm{MPa}$ and shear strain $375 \%$ ). 


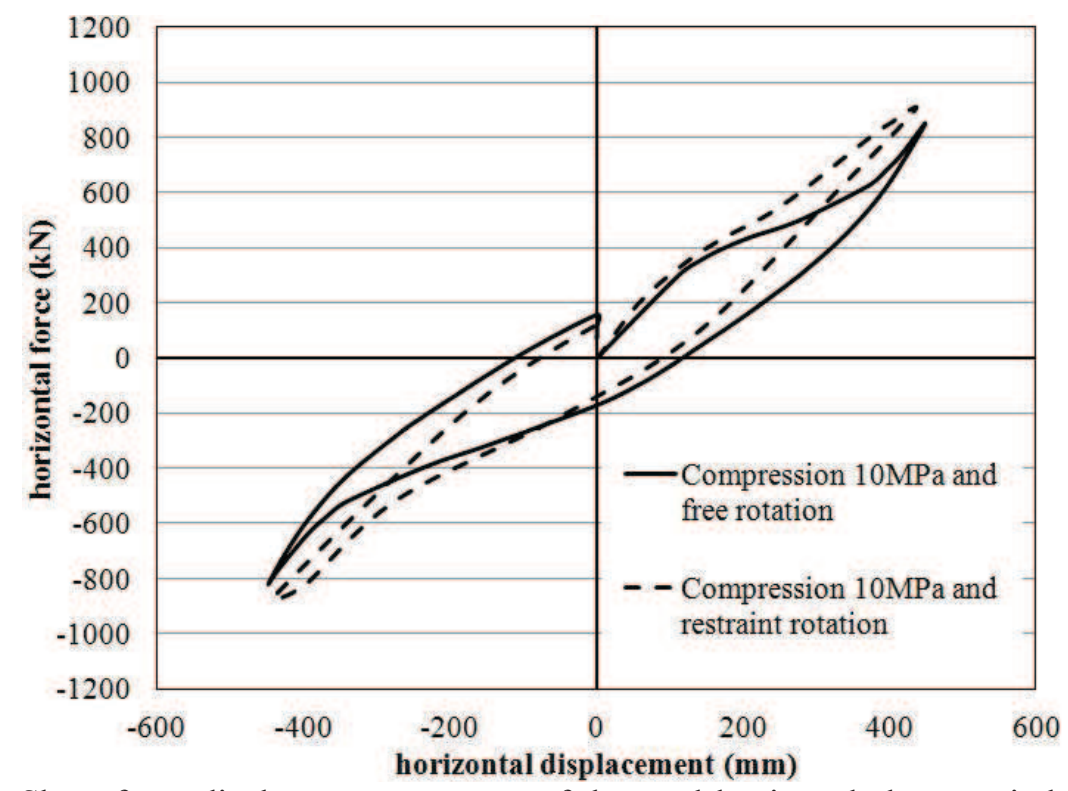

Figure 6. Shear force-displacement response of the steel-laminated elastomeric bearings for different boundary conditions (compression $10 \mathrm{MPa}$ and shear strain $375 \%$ ). 


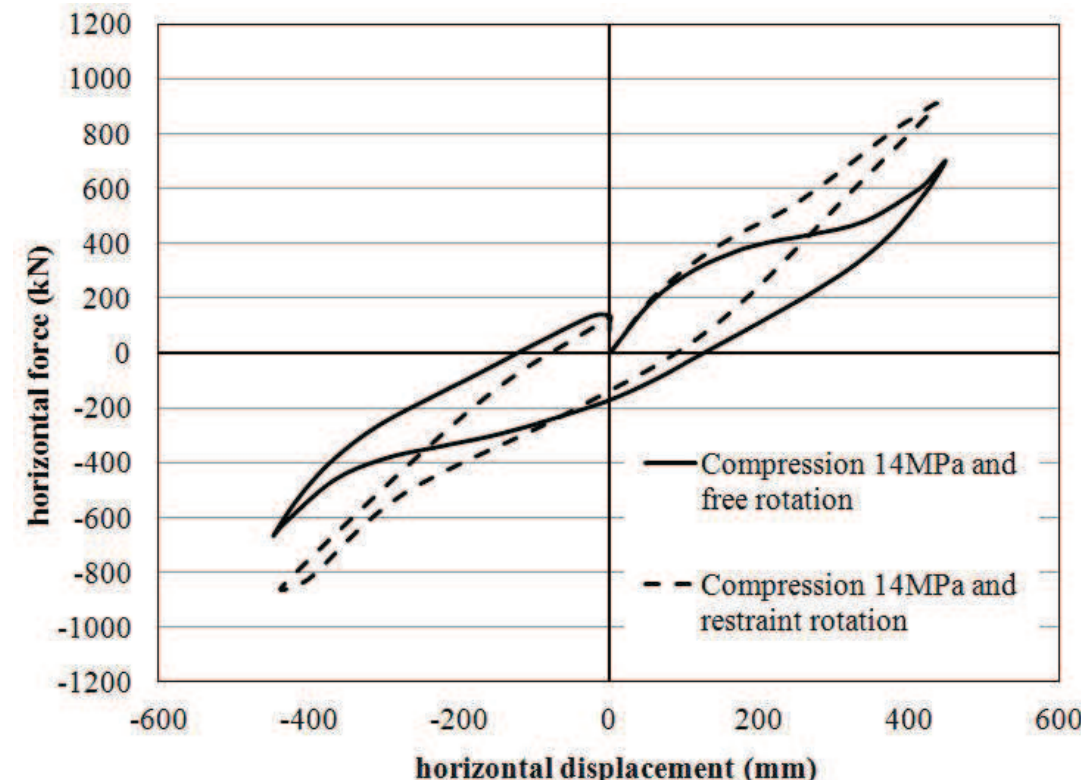

Figure 7. Shear force-displacement response of the steel-laminated elastomeric bearings for different boundary conditions (compression $14 \mathrm{MPa}$ and shear strain $375 \%$ ). 


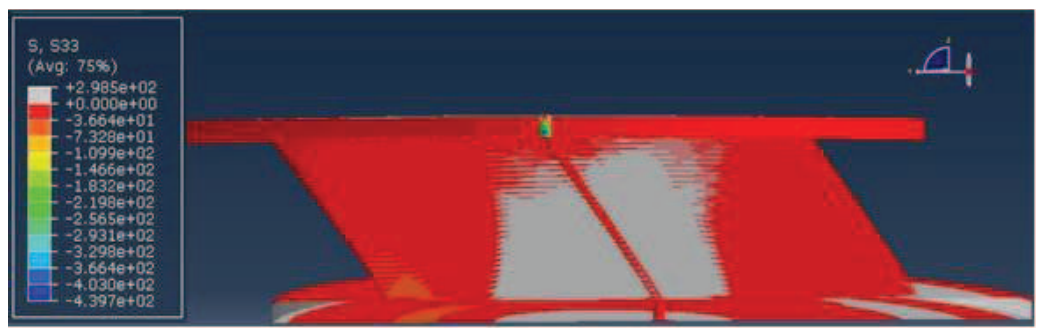

Figure 8. The axial stresses within the bearing for compressive load of $10 \mathrm{MPa}$, shear strain $125 \%$ and upper layer of the reference bearing free to rotate $\left(N L_{16}\right)$ (vertical section at bearing diameter). 


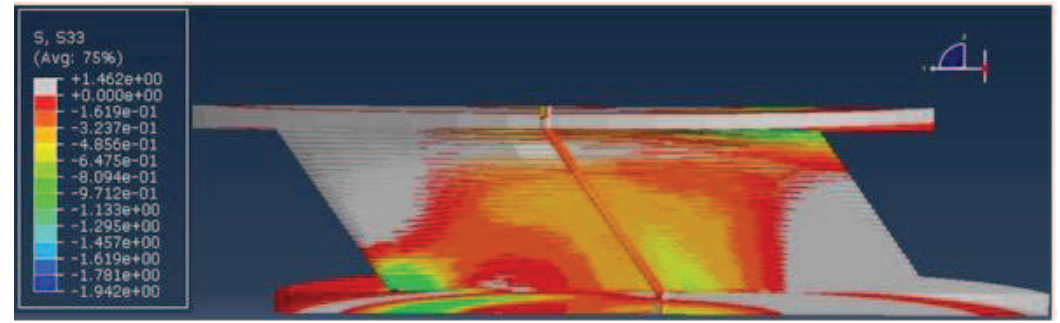

Figure 9. The axial stresses within the bearing for compressive load of $10 \mathrm{MPa}$, shear strain $125 \%$ and application of rotational restraint of the upper layer of the reference bearing $\left(N L_{17}\right.$ ) (vertical section at bearing diameter). 


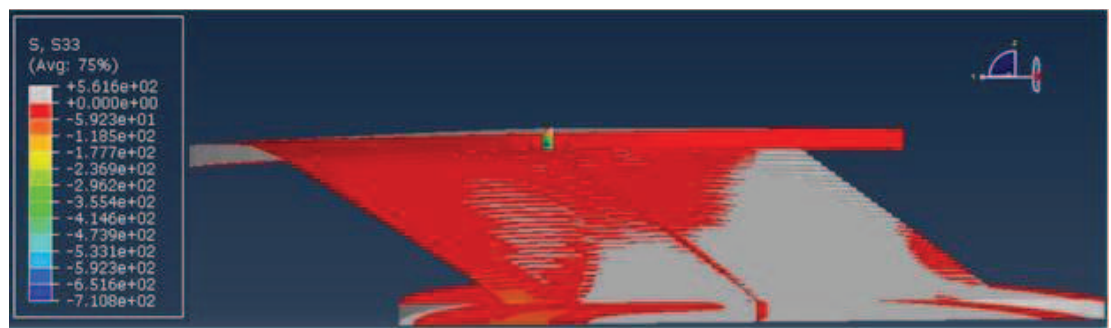

Figure 10. The axial stresses within the bearing for compressive load of $10 \mathrm{MPa}$, shear strain $250 \%$ and upper layer of the reference bearing free to rotate $\left(N L_{18}\right)$ (vertical section at bearing diameter). 


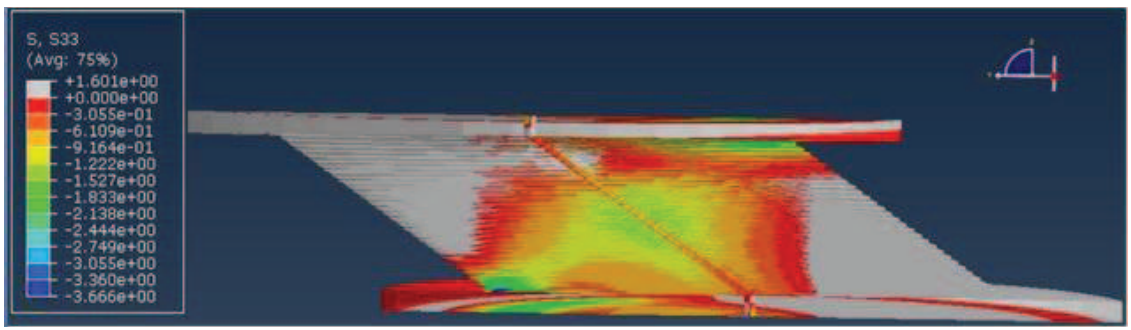

Figure 11. The axial stresses within the bearing for compressive load of $10 \mathrm{MPa}$, shear strain $250 \%$ and application of rotational restraint of the upper layer of the reference bearing $\left(N L_{19}\right.$ ) (vertical section at bearing diameter). 


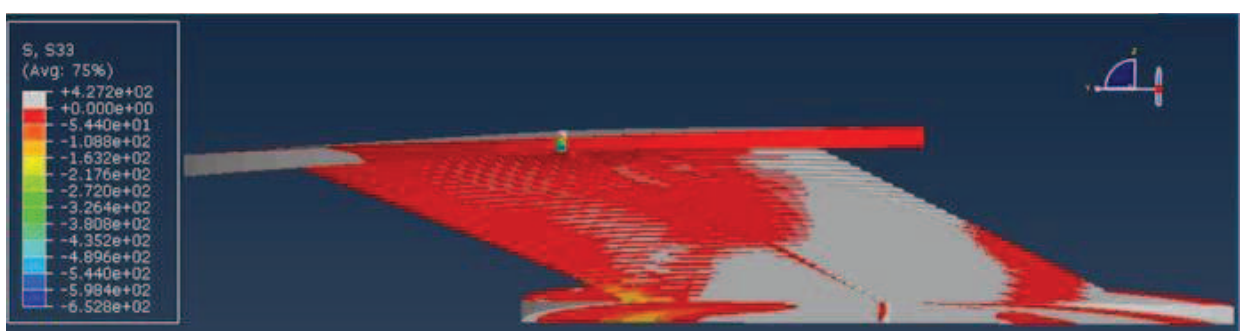

Figure 12. The axial stresses within the bearing for compressive load of $10 \mathrm{MPa}$, shear strain $375 \%$ and upper layer of the reference bearing free to rotate $\left(N L_{20}\right)$ (vertical section at bearing diameter). 


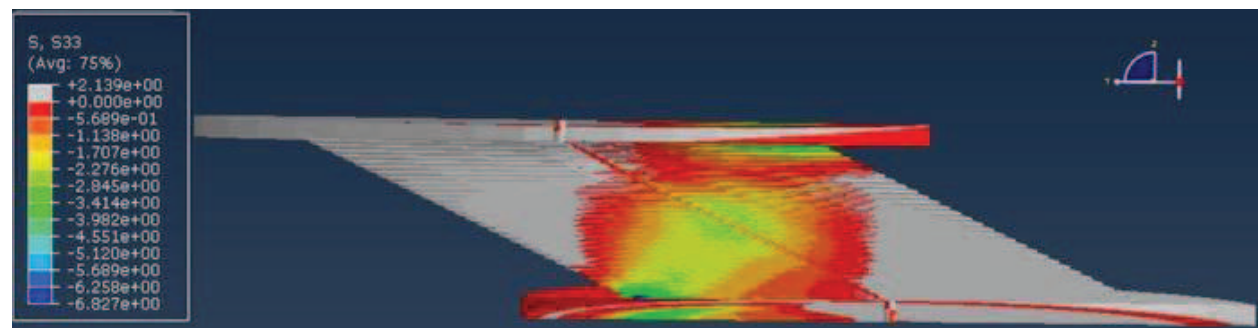

Figure 13. The axial stresses within the bearing for compressive load of $10 \mathrm{MPa}$, shear strain $375 \%$ and application of rotational restraint of the upper layer of the reference bearing $\left(N L_{21}\right.$ ) (vertical section at bearing diameter). 


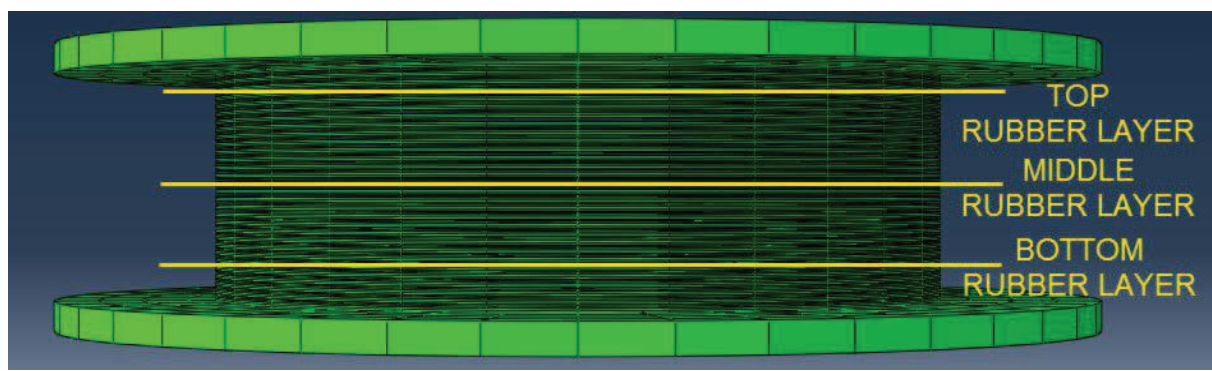

Figure 14. Three-dimensional view of the bearing indicating the position of the rubber layers shown in figures 15 and 16 below. 


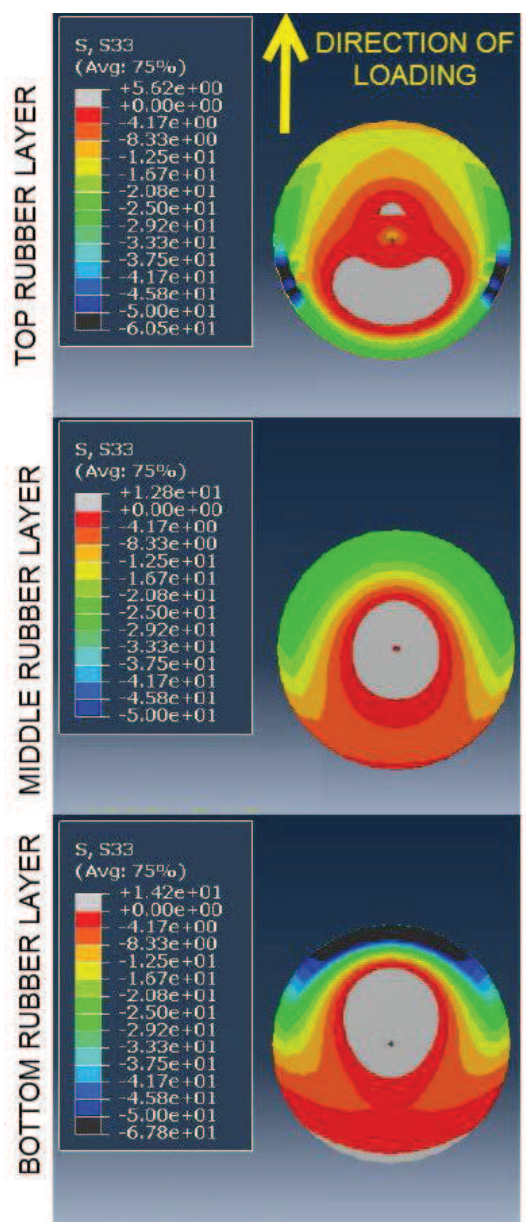

(a)

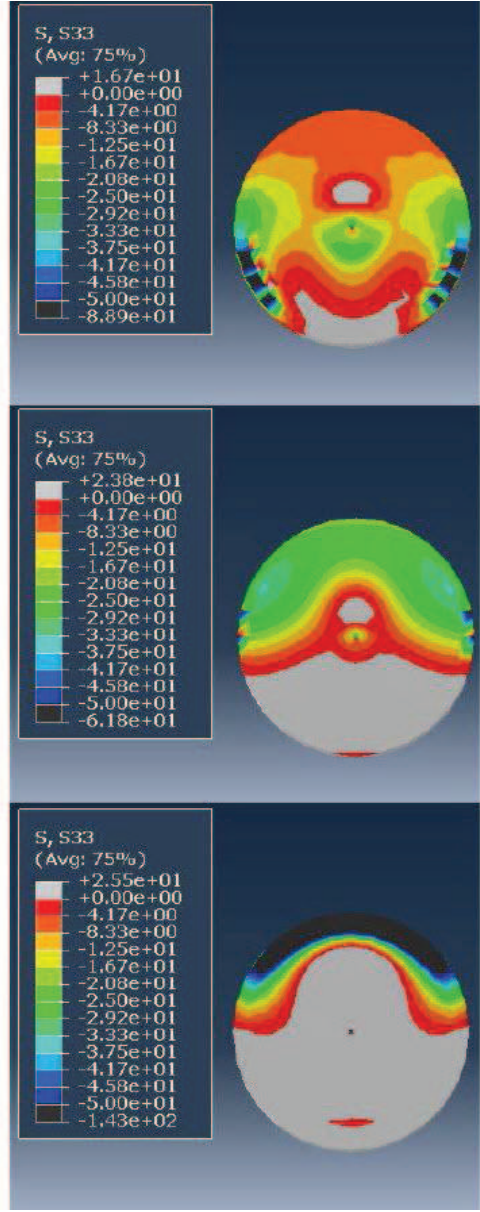

(b)

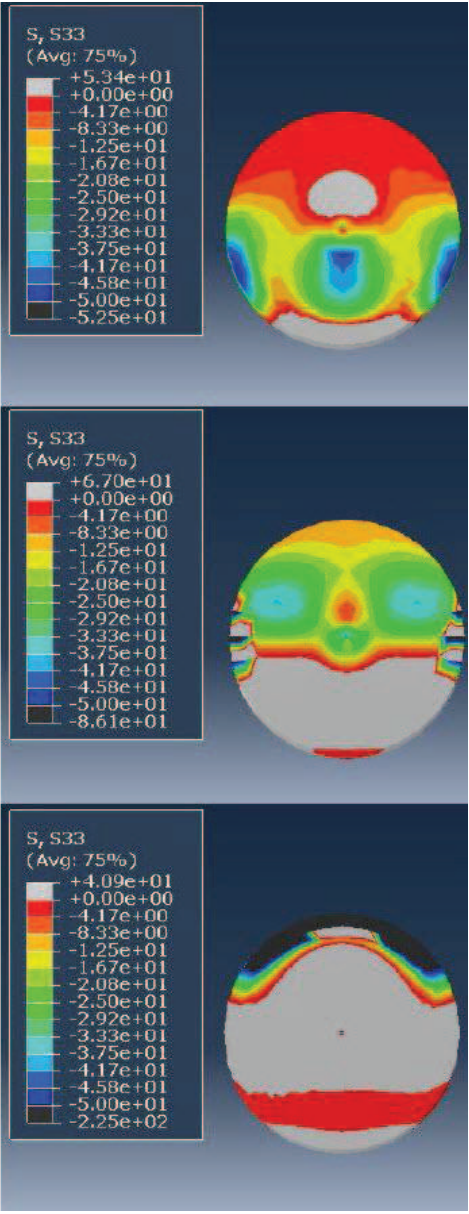

(c)

Figure 15. Axial stresses of the bearings at horizontal sections at the top, middle and bottom rubber layer. Gray areas indicate tensile stresses. Compressive load $10 \mathrm{MPa}$ and upper layer of the reference bearing free to rotate, shear strain: (a) $125 \%\left(N L_{16}\right)$, (b) $250 \%\left(N L_{18}\right)$, (c) $375 \%\left(N L_{20}\right)$. 


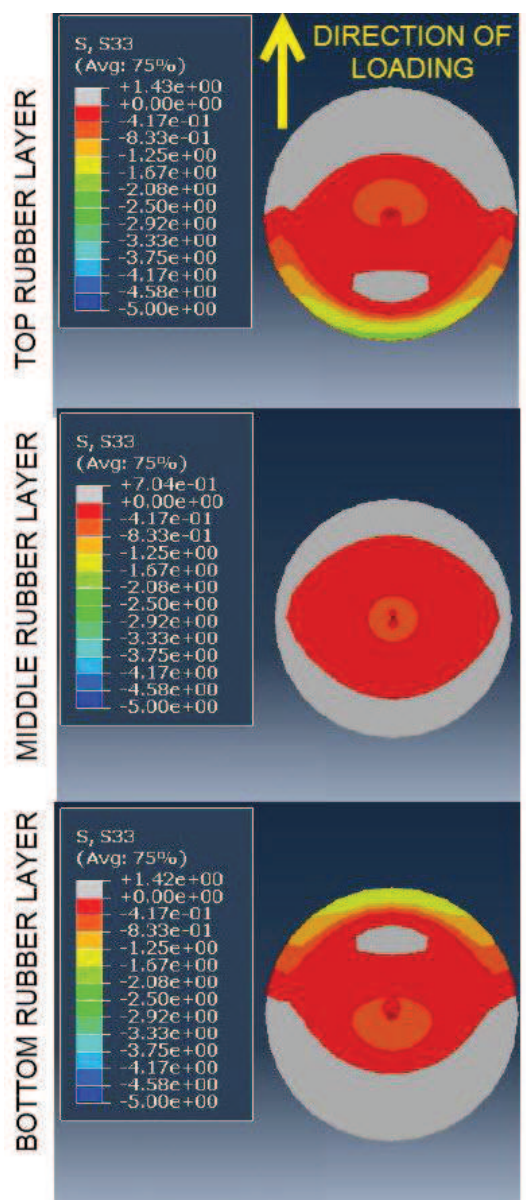

(a)

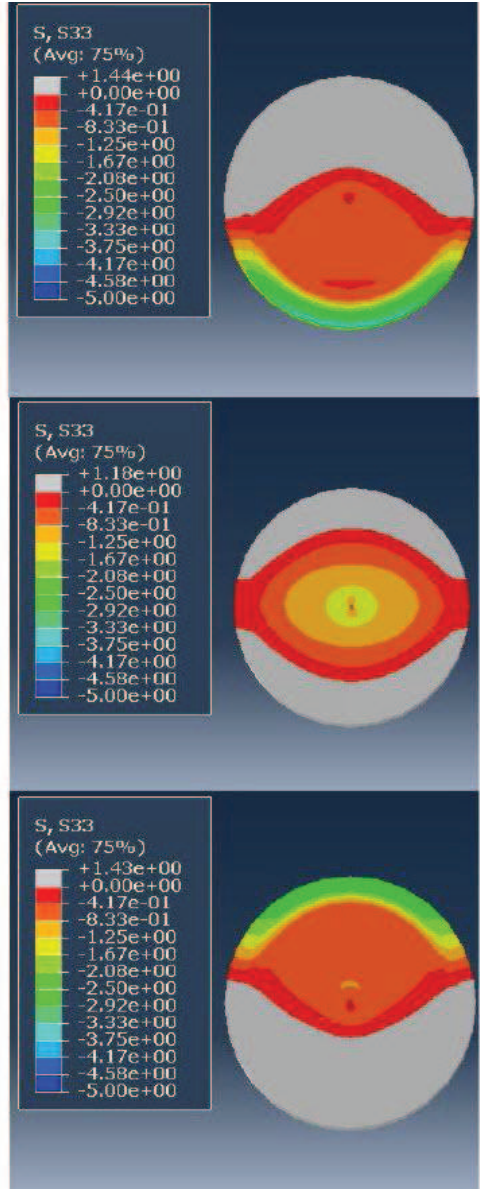

(b)

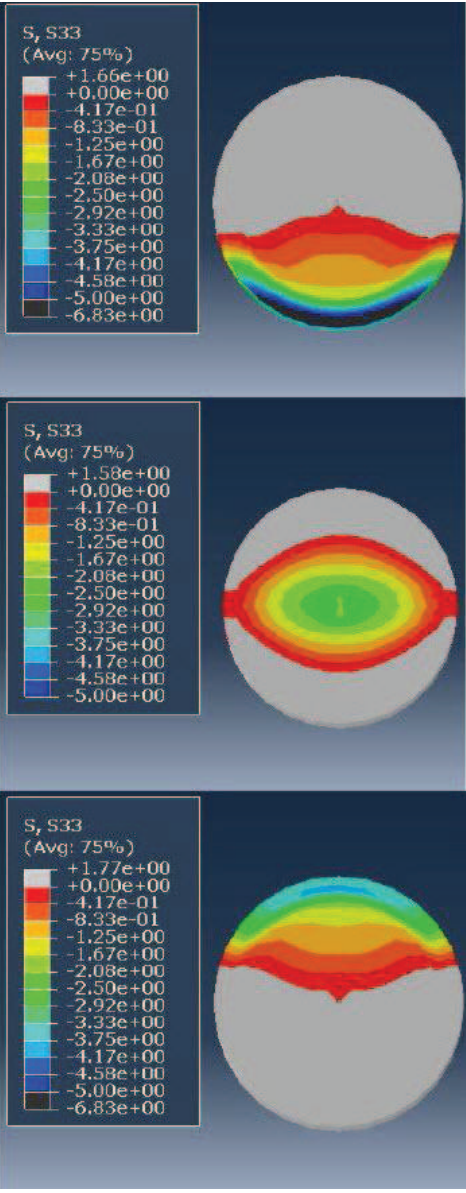

(c)

Figure 16. Axial stresses of the bearings at horizontal sections at the top, middle and bottom rubber layer. Gray areas indicate tensile stresses. Compressive load of $10 \mathrm{MPa}$, application of rotational restraint of the upper layer, shear strain: (a) $125 \%$ ( $\left.N L_{17}\right)$, (b) $250 \%\left(N L_{19}\right)$, (c) 375 $\%\left(N L_{21}\right)$. 
Click here to download Supplementary Material: 03. Title page.docx

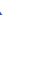
(1) (1) (1) (1) (1) (1) . $\sqrt{2}$

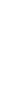
(1)

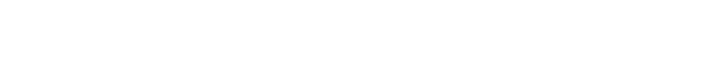

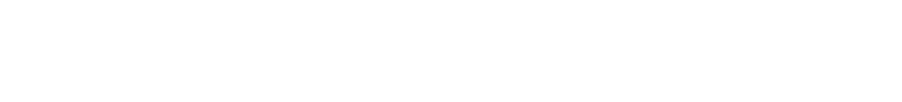
- 